\title{
Conceptual Design for a Dual-Bell Rocket Nozzle System Using a NASA F-15 Airplane as the Flight Testbed
}

\author{
Daniel S. Jones ${ }^{1}$ \\ NASA Armstrong Flight Research Center, Edwards, California, 93523 \\ Joseph H. Ruf ${ }^{2}$ \\ NASA Marshall Space Flight Center, Huntsville, Alabama, 35812 \\ Trong T. Bui, ${ }^{3}$ Martel Martinez, ${ }^{4}$ and Clinton W. St. John ${ }^{5}$ \\ NASA Armstrong Flight Research Center, Edwards, California, 93523
}

\begin{abstract}
The dual-bell rocket nozzle was first proposed in 1949, offering a potential improvement in rocket nozzle performance over the conventional-bell nozzle. Despite the performance advantages that have been predicted, both analytically and through static test data, the dual-bell nozzle has still not been adequately tested in a relevant flight environment. In 2013 a proposal was constructed that offered a National Aeronautics and Space Administration (NASA) F-15 airplane as the flight testbed, with the plan to operate a dual-bell rocket nozzle during captive-carried flight. If implemented, this capability will permit nozzle operation into an external flow field similar to that of a launch vehicle, and facilitate an improved understanding of dual-bell nozzle plume sensitivity to external flow-field effects. More importantly, this flight testbed can be utilized to help quantify the performance benefit with the dual-bell nozzle, as well as to advance its technology readiness level. Toward this ultimate goal, this paper provides plans for future flights to quantify the external flow field of the airplane near the nozzle experiment, as well as details on the conceptual design for the dual-bell nozzle cold-flow propellant feed system integration within the NASA F-15 Propulsion Flight Test Fixture. The current study shows that this concept of flight research is feasible, and could result in valuable flight data for the dual-bell nozzle.
\end{abstract}

\section{Nomenclature}

$\begin{array}{ll}\text { ACN } & =\text { altitude-compensating nozzle } \\ \text { AFRC } & =\text { Armstrong Flight Research Center (Edwards, California) } \\ \text { AoA } & =\text { angle of attack } \\ \mathrm{CB} & =\text { conventional-bell } \\ \mathrm{CCIE} & =\text { Channeled Centerbody Inlet Experiment } \\ \mathrm{CDE} & =\text { Cone Drag Experiment } \\ \mathrm{CFD} & =\text { computational fluid dynamics } \\ \mathrm{COPV} & =\text { composite overwrapped pressure vessel } \\ \mathrm{DOF} & =\text { degrees-of-freedom } \\ \mathrm{GN} & \\ \mathrm{I}_{\mathrm{sp}} & =\text { gaseous nitrogen } \\ \mathrm{LEO} & =\text { low-Earth orbit } \\ \mathrm{LMI} & =\text { Local Mach Investigation } \\ \mathrm{MEOP} & =\text { maximum expected operating pressure } \\ \mathrm{MSFC} & =\text { Marshall Space Flight Center (Huntsville, Alabama) }\end{array}$

${ }_{1}^{1}$ Aerospace Engineer, Aerodynamics and Propulsion Branch, P.O. Box 273/MS 4800-2228, AIAA Senior Member.

${ }^{2}$ Aerospace Engineer, ER42/Fluid Dynamics Branch Combustion Analysis Team, MS 4203, AIAA Member.

${ }^{3}$ Aerospace Engineer, Aerodynamics and Propulsion Branch, P.O. Box 273/MS 4840B, AIAA Senior Member.

${ }^{4}$ Aerospace Engineer, Operations Engineering Branch, P.O. Box 273/MS 4820.

${ }^{5}$ Aerospace Engineer, Aerodynamics and Propulsion Branch, P.O. Box 273/MS 4840B, AIAA Member. 


$\begin{array}{ll}\text { NASA } & =\text { National Aeronautics and Space Administration } \\ \text { NNPR } & =\text { normalized nozzle pressure ratio } \\ \text { NPR } & =\text { nozzle pressure ratio }\left(P_{c} / P_{a m b}\right) \\ \text { NTF } & =\text { Nozzle Test Facility } \\ \text { OML } & =\text { outer mold line } \\ P_{a m b} & =\text { ambient pressure } \\ P_{c} & =\text { nozzle chamber pressure } \\ \text { PFTF } & =\text { Propulsion Flight Test Fixture } \\ \text { PRA } & =\text { pressure reducing assembly } \\ \text { RAGE } & =\text { Rake Airflow Gage Experiment } \\ \text { RFS } & =\text { rocket forebody simulator } \\ \text { SSME } & =\text { Space Shuttle Main Engine } \\ \text { STS } & =\text { Space Transportation System } \\ \text { TRL } & =\text { technology readiness level }\end{array}$

\section{Introduction}

$\mathrm{D}$ evelopment of the dual-bell rocket nozzle has been proposed, including the goal of advancing the technology readiness level (TRL) of the dual-bell nozzle through flight testing and flight research in a relevant environment. ${ }^{1}$ A more thorough investigation on the performance of the dual-bell nozzle is warranted since this nozzle has been predicted to offer a performance advantage over the conventional-bell (CB) nozzle. If the performance benefit of the dual-bell nozzle is proven in a relevant environment, utilization of this technology could lead to a capability of delivering higher mass payloads to low-Earth orbit (LEO).

The dual-bell nozzle is one type of altitude-compensating nozzle (ACN), which has a fixed geometry with an inner contour consisting of two overlapped bells. During rocket ascent at low altitudes, the dual-bell nozzle operates in mode 1, only utilizing the smaller bell of the nozzle. During rocket ascent at higher altitudes, the dual-bell nozzle operates in mode 2, also utilizing the larger bell of the nozzle. The inherent dual-mode operation of the dual-bell nozzle theoretically permits near optimal expansion at two altitudes, and overall, a higher mission integrated performance over the CB nozzle since the flow within the dual-bell nozzle will never be significantly over- or under-expanded. The concept of the dual-bell nozzle was first proposed in 1949, offering a potential method of mitigating the high performance losses incurred by the CB nozzle. ${ }^{2}$ Since then, analytical studies and static tests with the dual-bell nozzle have continued worldwide, but to the authors' knowledge, the dual-bell nozzle has still not been adequately tested in a relevant flight environment.

The National Aeronautics and Space Administration (NASA) Marshall Space Flight Center (MSFC) (Huntsville, Alabama) is one of the few organizations that has complemented their analytical effort on the dual-bell nozzle with static tests to verify their performance predictions. MSFC conducted static testing of the dual-bell nozzle at the MSFC Nozzle Test Facility (NTF), utilizing a non-reacting flow which exhausted from the nozzle into a quiescent environment. Nozzle testing was conducted over a wide range of nozzle pressure ratio (NPR) conditions, while quantifying the nozzle performance and flow behavior at each condition. Figure 1 shows a photo of the test setup at the MSFC NTF with a dual-bell nozzle. Testing with a similar CB nozzle was also conducted at the MSFC NTF. During these tests, the dual-bell nozzle proved to provide a greater performance than the CB nozzle over a range of NPR conditions.

The NASA Armstrong Flight Research Center (AFRC) (Edwards, California), formerly the NASA Dryden Flight Research Center, has a unique capability with its fleet of F-15 airplanes (McDonnell Douglas, now The Boeing Company, Chicago, Illinois), one of which can be used as a flight testbed for dual-bell rocket nozzle research. ${ }^{1}$ Captive-carried flight research expertise at AFRC led to the creation of the Propulsion Flight Test Fixture (PFTF), which was specifically created to facilitate the advancement of propulsion-focused technologies through captivecarried flight research. Figure 2 shows a photo of the PFTF (in black) mated to the centerline pylon of an F-15 airplane, while conducting captive-carried flight research with a simulated rocket (in red). ${ }^{3}$

Several of the F-15/PFTF capabilities and limitations for the dual-bell rocket nozzle flight system have been documented. ${ }^{1}$ Among these documented capabilities and limitations are: (1) an overview of the F-15/PFTF capability; (2) the proposed nozzle placement and sizing criteria; (3) the PFTF internal capacity; (4) the PFTF thrust limitations of the force balance (a system that permits dual-bell nozzle thrust forces to be measured in flight); and (5) the F-15/PFTF flight envelope. These criteria were used to develop the conceptual design presented in this paper.

The flight-research campaign is designed to include three phases, which will all require tests at various flight conditions. These three flight-research phases are as follows: (Phase I) initial flight research to quantify the external 
(local) flow-field conditions near the nozzle; (Phase II) flights while operating cold flow through various nozzles; and (Phase III) flights while operating reacting flow through various nozzles. Rationale for conducting each of the three phases of the flight-research campaign has been documented, as well as the rationale for conducting dual-bell rocket nozzle research through captive-carried flight. ${ }^{1}$ The conceptual design presented within this paper covers Phase I and Phase II of the flight-research campaign. The conceptual design for Phase III of the flight-research campaign will be detailed in a future publication.

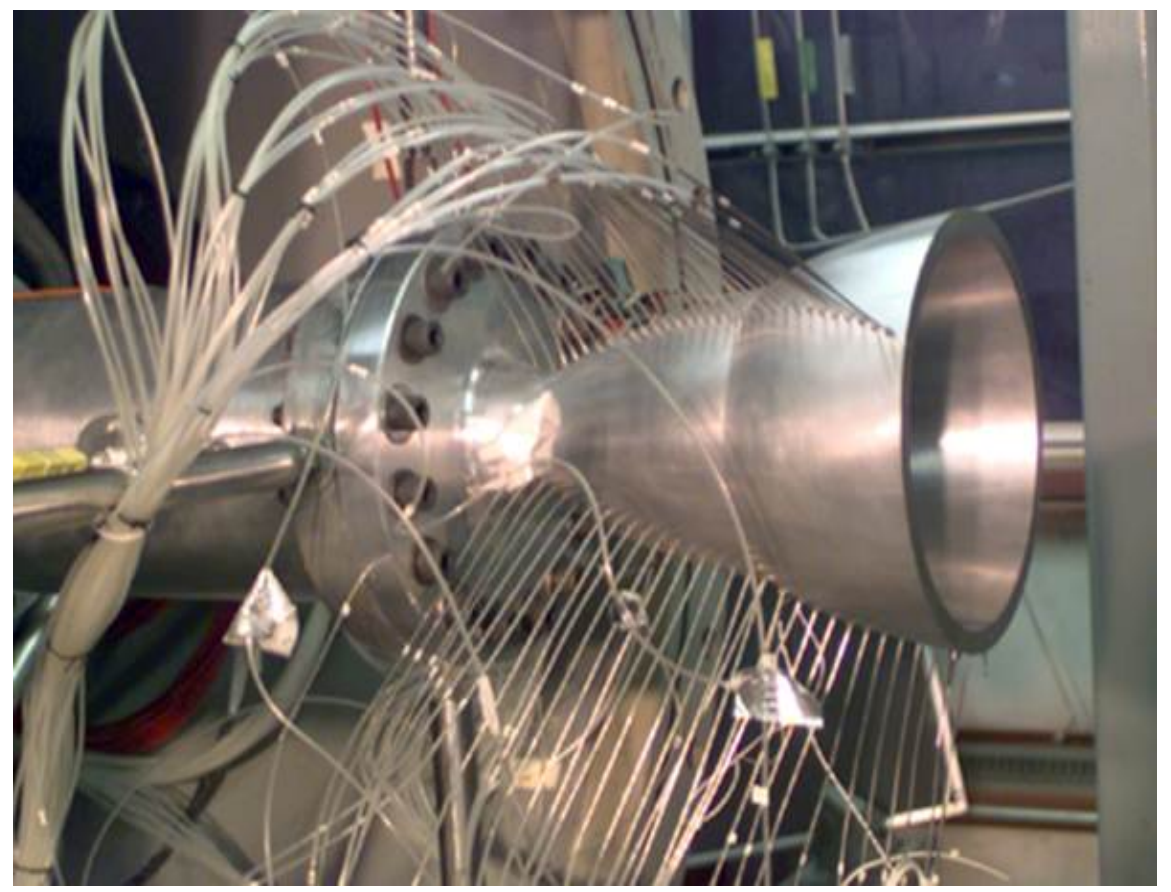

Figure 1. Dual-bell nozzle during testing at the NASA MSFC NTF.

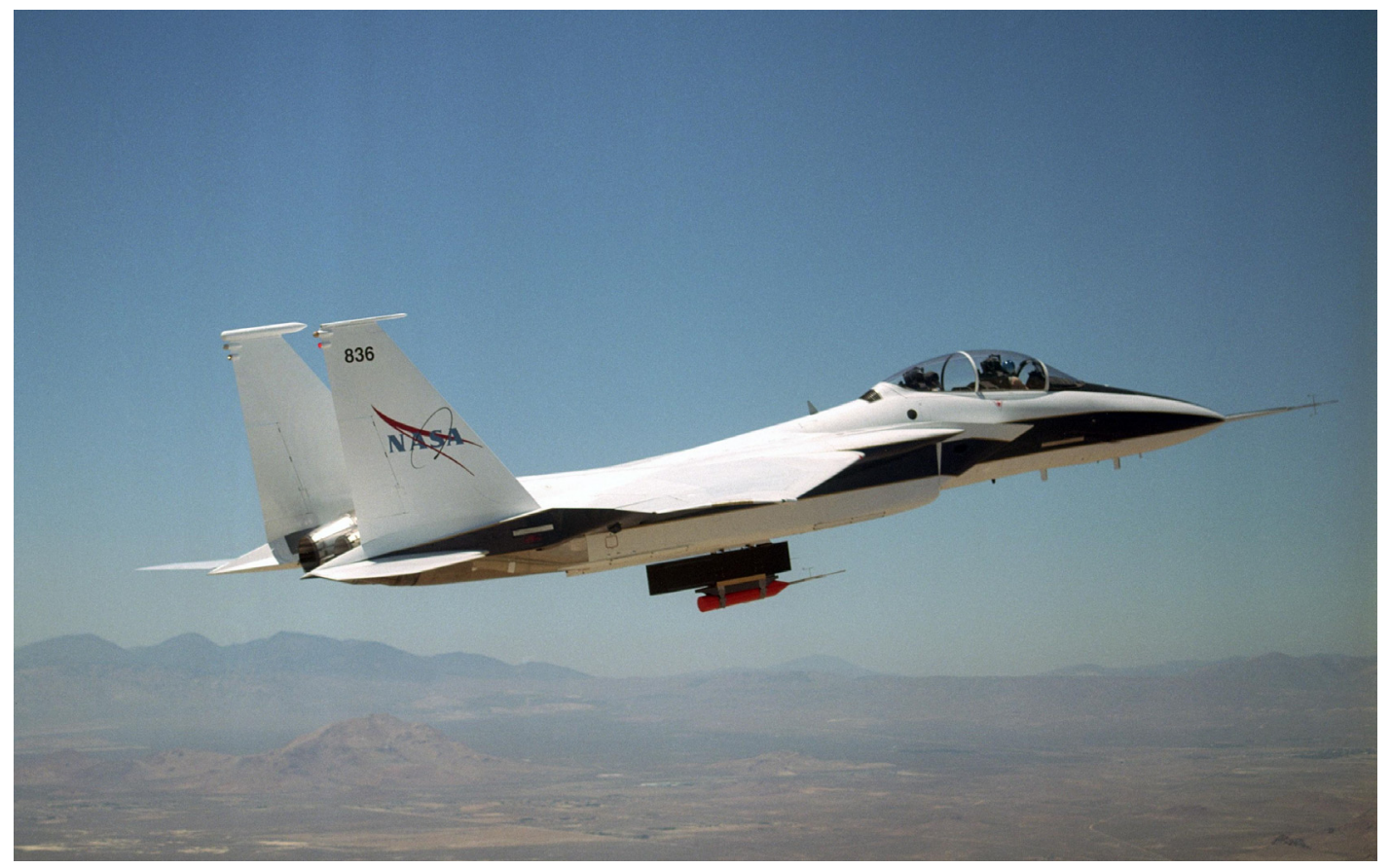

Figure 2. Photo of a NASA AFRC F-15 airplane, with the PFTF and a simulated rocket. 


\section{Conceptual Design for the External Flow-Field Flights (Phase I)}

Phase I of the dual-bell nozzle flight-research campaign will be conducted to quantify the local external flow-field conditions under the F-15/PFTF near the dual-bell nozzle. A survey of the external flow field is crucial to a greater understanding of the nozzle plume transitional behavior and must be understood prior to flights which include nozzle operation. This section will provide details on three main topics related to the Phase I flight-research campaign: (1) previous flight experiments that have been conducted with the F-15/PFTF; (2) the conceptual design for the dual-bell nozzle external flow-field flights; and (3) the initial results from the external flow-field predictions.

\section{A. Previous Flight Experiments Utilizing the F-15/PFTF}

The conceptual design for the Phase I flight system is based on the utilization of existing flight-proven hardware, with the F-15/PFTF as the flight testbed. Combined with one of the AFRC F-15 research airplanes, the PFTF provides an innovative and cost effective method for conducting flight testing and flight research of advanced propulsion concepts. AFRC expertise with captive-carried flight research led to the creation of the PFTF, which has been integrated with the centerline pylon of an F-15 airplane. The PFTF also has a six-degrees-of-freedom (6-DOF) in-flight force measurement capability for a propulsion flight research experiment carried below the PFTF. ${ }^{4}$ The PFTF has been utilized for captive-carried flight research with four previous experiments:

1) The Cone Drag Experiment (CDE), in which a cylindrical duct with a conical nose cap was used as a simulated rocket. This flight research facilitated the validation of the PFTF integral 6-DOF force balance system against aerodynamic and inertial forces in flight. ${ }^{5}$

2) The Local Mach Investigation (LMI) flights, in which an air data boom was attached to the front of a simulated rocket. This flight research led to a quantified assessment of the local Mach number and the local flow angle at a single point under the F-15/PFTF over a wide range of flight conditions. ${ }^{6}$

3) The Rake Airflow Gage Experiment (RAGE), in which a cruciform array of nine five-hole conical probes was attached to the front of a simulated rocket by a cylindrical boom. This flight research led to a quantified assessment of the local flow conditions at the aerodynamic interface plane of an advanced inlet experiment, over a local range of Mach 1.45 through Mach 1.6. ${ }^{7}$

4) The Channeled Centerbody Inlet Experiment (CCIE), in which an advanced experimental inlet was mounted under the PFTF. This flight research led to a quantified assessment of the airflow through an advanced experimental inlet, which was also compared to the airflow through a standard inlet. The CCIE flight hardware included two interchangeable center bodies, which were installed in an air inlet tube. One center body was channeled, and the other center body was a conventional smooth shape. Slots cut along the length of the channeled center body simulated a simple device that, in an actual inlet, would allow optimization of the amount of air flowing into the engine. ${ }^{8}$

\section{B. External Flow-Field Conceptual Design}

Figure 3 shows a sketch of the conceptual design of an F-15 airplane in the ACN dual-bell nozzle flight-research configuration, which has great similarities to the previous flight-research experiments, as noted above. The conceptual design for the flight-research testbed is based on the philosophy of utilizing existing flight-proven hardware to the greatest extent possible. The rationale behind this philosophy is three-fold: (1) to reduce cost; (2) to minimize schedule; and (3) to mitigate risk.

The ACN-specific hardware that is captive-carried by an F-15 airplane is called the ACN stack, and consists of the following three primary components: (1) the PFTF; (2) the PFTF experiment adapter; and (3) the rocket forebody simulator (RFS). Figure 3 shows the ACN stack, which is mounted to an F-15 airplane via the centerline pylon. Both the airplane and the RFS will have air data booms to measure the incoming Mach number and flow angles, with the airplane air data boom measuring freestream conditions, and the RFS air data boom measuring incoming RFS local flow conditions. The rocket nozzle will be mounted in the aft-region of the RFS, with the nozzle exit plane coplanar with the RFS close-out plate. For the Phase I flow field survey flights, the entire RFS outer mold line (OML) will be heavily instrumented, especially near the nozzle exit plane, such that the local flow field can be quantified prior to nozzle operational flights. Although previous flight experiments have measured the local flow field near the front of the RFS (via an air data boom, or a rake), the flow field near the aft region of the RFS has never been quantified. The same RFS OML pressure instrumentation plan will be used for all three phases of flight research, to facilitate comparisons. The RFS OML instrumentation will be used to determine the local ambient pressures along the RFS, especially near the nozzle experiment. Data from this instrumentation will also lead to the validation of computational fluid dynamics (CFD) predictions and facilitate refined analytical predictions prior to flight activity with nozzle operation. 


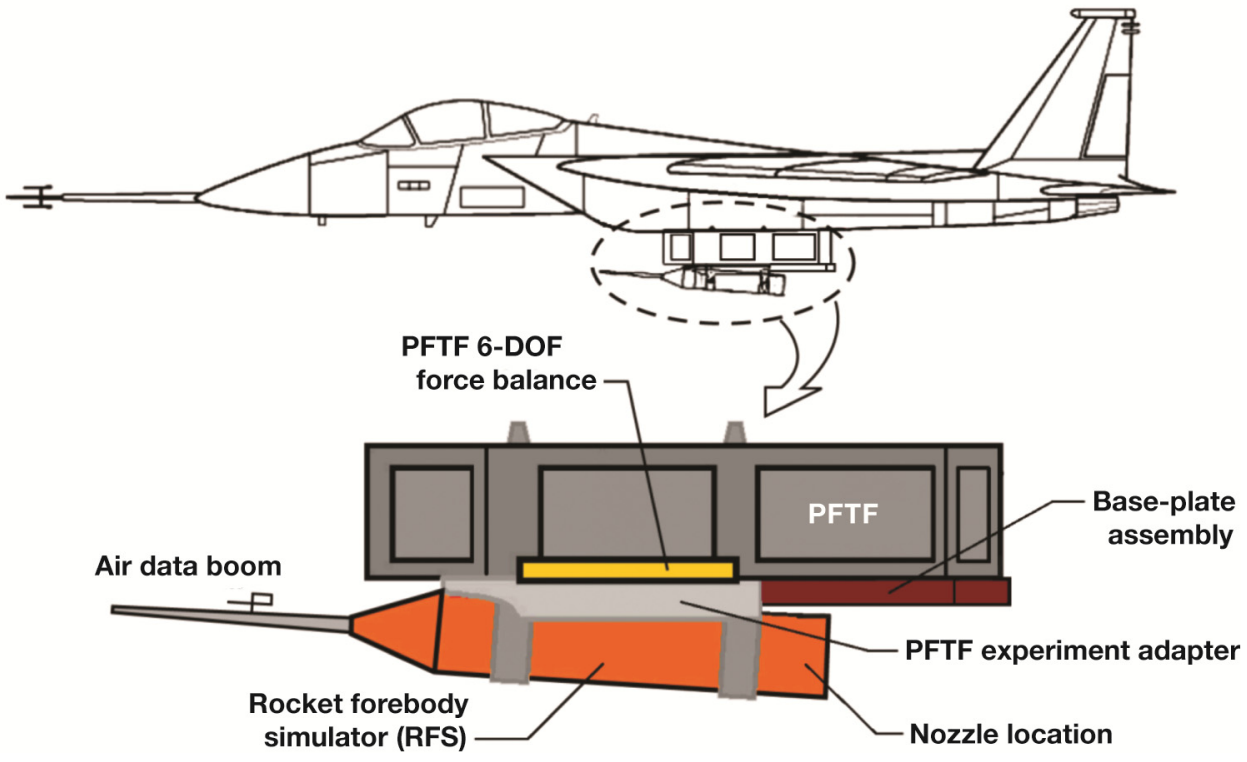

Figure 3. F-15 airplane in the ACN dual-bell nozzle flight-research configuration.

The PFTF has an internal capacity that can be used for the dual-bell rocket nozzle propellant feed system, which will be described in greater detail in the next section of this paper. The PFTF main structure was fabricated from a solid billet of 6061-T6 aluminum, with an overall length of 107 inches, an overall height of 19 inches, and an overall width of 10 inches. The RFS will be mounted underneath the PFTF, and will be utilized to spatially and inertially simulate a rocket utilizing a dual-bell rocket nozzle in flight. The RFS has a cylindrical diameter of 10 inches and a 60 degree half-angle conical nose with an air data boom. All ACN flights (including non-operational nozzle flights) will utilize the PFTF 6-DOF force balance system to measure forces in flight. The limitations and accuracy of the force balance have previously been documented. ${ }^{1}$ For Phase I flights, the force balance will measure aerodynamic and inertial forces on the RFS, whereas the Phase II and Phase III flights will utilize the force balance to also measure dual-bell nozzle thrust forces in flight.

Figures 4(a) and 4(b) show external images of the ACN conceptual design. Figure 4(a) shows a rear-isometric view of the ACN stack, and Fig. 4(b) shows a zoomed-in view with the dual-bell rocket nozzle installed within the aft section of the RFS. The purpose of the RFS is partially to help simulate a rocket in flight and aid in aligning the local flow field as it approaches the nozzle exit plane. The RFS will also be utilized to house the propellant feed system plumbing from the PFTF to the rocket nozzle, as well as to house the routing of instrumentation. As noted earlier, the conceptual design of the RFS also includes an air data boom, although an air data boom is not shown in Fig. 4(a).

From Fig. 4(a) and 4(b), one can note the slight nose-up attitude of the RFS. Flight research with previous experiments utilized a nose-up attitude to align the forward end of the simulated rocket with the local flow field under the F-15/PFTF in that region, due to the local flow-field downwash from the F-15 airplane. The existing design allows for the articulation of this angle prior to flight, up to an inclination angle of five degrees with respect to the PFTF. The appropriate angle will be determined and set prior to flight to align the primary axis of the RFS with the local flow field near the nozzle for the flight-test condition planned. As noted earlier, the external (local) flow field is expected to have a significant effect on dual-bell nozzle plume behavior, including the dual-bell nozzle plume mode transition. In addition to the research benefit of aligning the nozzle with the external flow field, the RFS inclination angle also provides a flight-safety benefit by providing a greater separation of the nozzle plume from the F-15/PFTF flight hardware for nozzle operational flights.

The primary objective of the Phase I flow-field survey flights is to obtain the local flow field pressure data underneath the F-15/PFTF in preparation for future nozzle operational flights. CFD analysis has been completed to help predict this flow field in preparation for Phase I flight activity, and Phase I flight data will lead to the validation of this analysis. Flight data and CFD analysis will lead to a more thorough understanding of dual-bell nozzle plume sensitivity to local flow-field effects. 


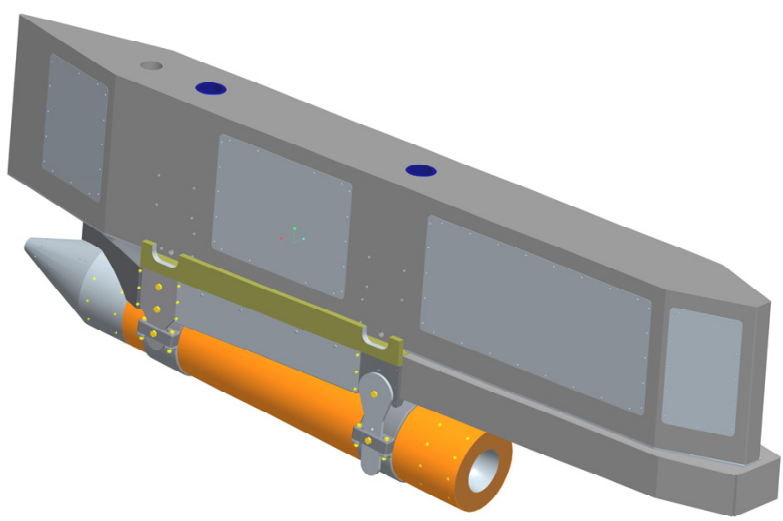

a) Rear-isometric view of ACN stack.

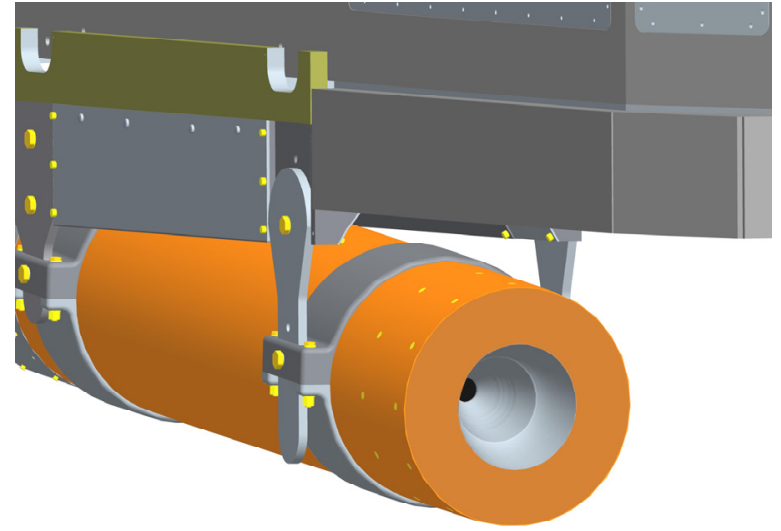

b) Zoomed-in rear-isometric view of $\mathrm{ACN}$ stack, showing dual-bell nozzle.

Figure 4. Conceptual design of ACN stack.

As noted earlier, the conceptual design for the flight-research testbed is based on the philosophy of utilizing existing flight-proven hardware to the greatest extent possible. Following this philosophy, a thorough inventory of existing flight hardware was taken against the Phase I conceptual design. The conclusion of this inventory led to the Phase I conceptual design shown in Fig. 3, Fig. 4(a), and Fig. 4(b). With the exception of the base-plate assembly (labeled in Fig. 3), all components have already been flight-proven.

\section{Initial External Flow-Field Predictions}

As can be seen in Fig. 3, the ACN exit plane is not exposed to the incoming freestream static pressure, but rather, it is subjected to flow perturbations caused by the F-15 airplane, the centerline pylon, the air data booms, the PFTF, the PFTF adapter, and the RFS. ACN operation greatly depends on the nozzle exit pressure, and accurate predictions of this exit pressure are required for the design of the nozzle and the propellant feed system, as well as for the final selection of the flight-test conditions required. The main objective of this initial analysis was to determine the flowfield effects caused by the F-15 airplane with the ACN stack, and ultimately the local flow-field conditions near the ACN exit plane. This initial flow-field analysis includes:

1) airplane-only inviscid/Euler CFD analysis for the airplane with blocked airplane inlets,

2) airplane plus ACN stack inviscid/Euler CFD analysis for the airplane and the ACN stack with blocked airplane inlets, with the ACN not operating, and

3) airplane plus ACN stack inviscid/Euler CFD analysis for the airplane and the ACN stack with blocked airplane inlets, with the ACN operating.

In addition, analysis is currently underway to determine the airplane and the ACN stack viscous/Navier-Stokes CFD flow-field predictions with and without experimental nozzle operation. Both the flow viscosity and the nozzle plume affect the base flow of the RFS and will influence the nozzle exit pressure. Therefore, these considerations will be included in a separate analysis. Finally, all CFD predictions will be validated using the Phase I flow field survey flight data.

All nozzle operation with an F-15 airplane will occur during a low angle of attack (AoA), and the local flow field is expected to remain mostly attached. Based on this assumption, the initial predictions were completed with an inviscid/Euler CFD analysis, and should yield satisfactory results for this preliminary design and sizing effort.

A comparison of the airplane-only and airplane plus ACN stack predictions was initially conducted to isolate the effects of the ACN stack on the ACN exit plane, and permit the investigation of possible flow anomalies. Blocked airplane inlets potentially produce the most disturbances to the local flow field underneath the airplane, so the addition of blocked airplane inlets was included in this initial analysis effort. No airplane engine parameters were needed for this blocked airplane inlet approximation.

The Star-CCM+ polyhedral finite-volume unstructured CFD code was used for this analysis effort. Figure 5 illustrates an inviscid/Euler CFD grid that was created for an F-15 airplane and the complete experimental stack. Since only changes in AoA are considered, only half of the airplane is modeled. The base-plate assembly was not modeled in the current CFD analysis, but this difference in the model is not expected to change the basic 
conclusions for the current results. The base-plate assembly should be included in future CFD analysis should it become a permanent fixture in the flight experiment.

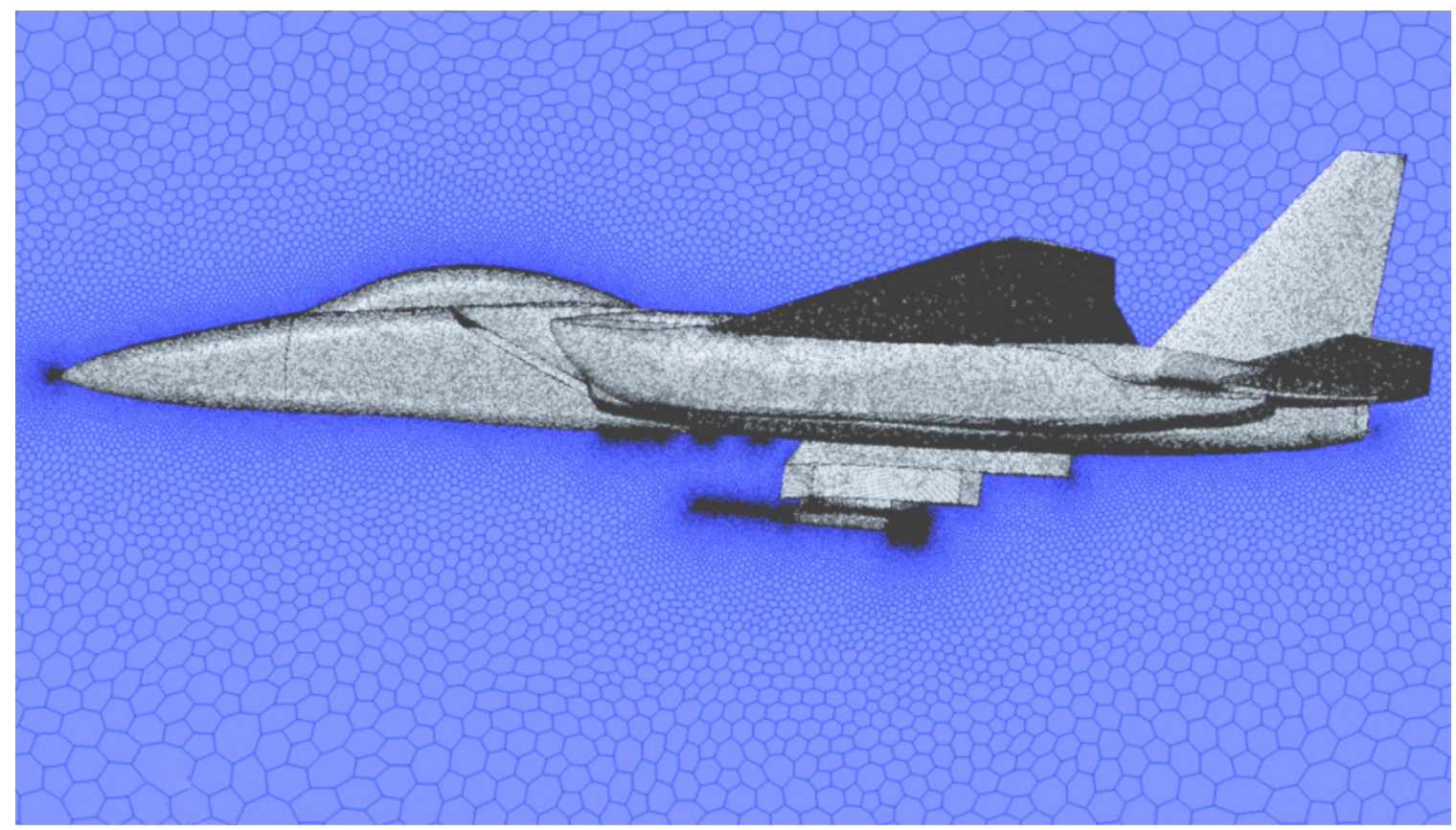

Figure 5. Star-CCM+ inviscid/Euler CFD grid for an F-15 airplane and the full experimental stack.

Two different flight-test conditions were initially considered for this analysis to gain a greater understanding of the local flow field near the nozzle exit plane:

1) $46 \mathrm{kft}$ altitude, Mach 0.9, and 4.2-deg airplane AoA.

2) $46 \mathrm{kft}$ altitude, Mach 1.2, and 2.6-deg airplane AoA.

The $46 \mathrm{kft}$ altitude was selected to provide a clean, undisturbed freestream static pressure value of 2 psi used in the current nozzle and propellant feed system design and sizing effort. The transonic and supersonic flight conditions were selected to evaluate compressibility effects on the ACN exit pressure. For the two flight conditions under consideration, the corresponding airplane AoA values were found from the F-15 airplane flight simulation deck in the Aerodynamics and Propulsion Branch at NASA AFRC. Figures 6(a) and 6(b) illustrate some preliminary CFD predictions for the local flow field underneath a clean F-15 airplane. The static pressure contours on the airplane for the Mach 0.9 flight condition are shown in Fig. 6(a), and the static pressure contours for the Mach 1.2 flight condition are shown in Fig. 6(b). It can be seen that the flow disturbances in the supersonic flight condition are more pronounced than the transonic flight condition. For each condition, an average of pressures was obtained in the location of the nozzle exit plane. The averaged nozzle exit pressure for the transonic flight condition is $1.93 \mathrm{psi}$, and is only slightly less than the freestream static pressure value of 2 psi. For the supersonic flight condition, the averaged nozzle exit pressure value is $1.70 \mathrm{psi}$ and is further below the freestream static pressure. Despite the disturbances created by the airplane nose and inlet, it can be seen from the streamlines that smooth flow exists underneath the airplane for both the transonic and supersonic cases.

It can be seen in both cases that the blocked airplane inlet produces a very large disturbance in the pressure field underneath the airplane, and therefore, there are large variations in static pressure in the streamwise direction. However, the location of the nozzle exit is in an area where the static pressure is relatively close to the freestream static pressure value of $2 \mathrm{psi}$, for both cases. These preliminary results indicate a well-chosen location for the dual-bell nozzle experiment, with a relatively benign local flow field. 


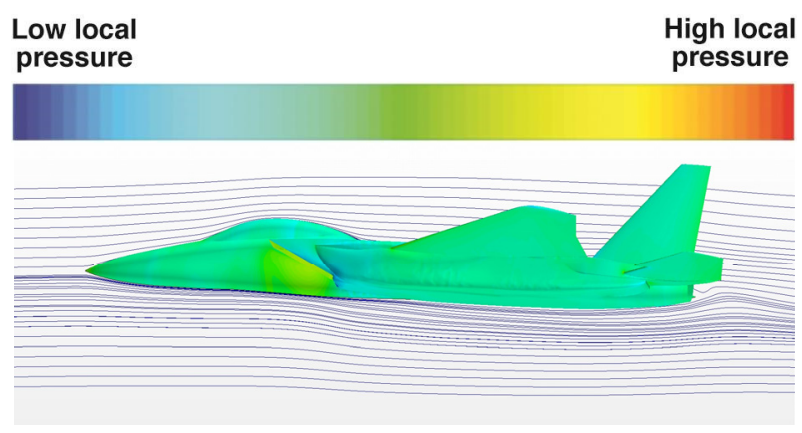

a) Mach 0.9, averaged $\mathrm{ACN}$ exit pressure $=1.93$ psi.
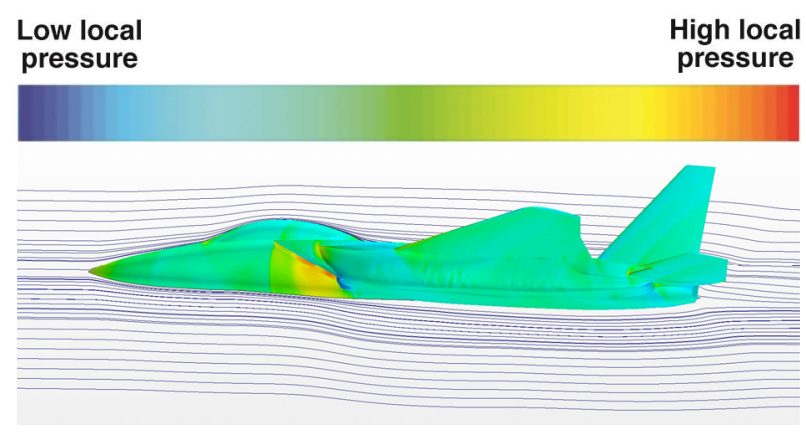

b) Mach 1.2, averaged $\mathrm{ACN}$ exit pressure $=1.70 \mathrm{psi}$.

Figure 6. Static pressure contours from inviscid/Euler clean F-15 airplane analysis, both at a freestream static pressure of 2 psi.

It is expected that the inclusion of the ACN stack, as well as the ACN plume, will change the ACN exit pressure. Therefore, preliminary inviscid/Euler CFD solutions were obtained for an F-15 with the full experimental stack. Figures 7(a) and 7(b) illustrate some preliminary CFD predictions for the local flow field underneath an F-15 airplane and the ACN stack with no flow through the ACN. The static pressure contours on the airplane for the Mach 0.9 flight condition are shown in Fig. 7(a), and the static pressure contours for the Mach 1.2 flight condition are shown in Fig. 7(b). As expected, the local ACN exit pressures are further below the clean airplane only results that are shown in Fig. 6. The averaged ACN exit pressure for the transonic flight condition is 1.74 psi, and the supersonic flight condition is $0.98 \mathrm{psi}$. The supersonic value is only about half of the freestream static pressure, so the stack is producing more disturbance than just the clean airplane. In all cases, the flow streamlines show that the flow remains nice and smooth beneath the airplane, even with the full ACN stack.

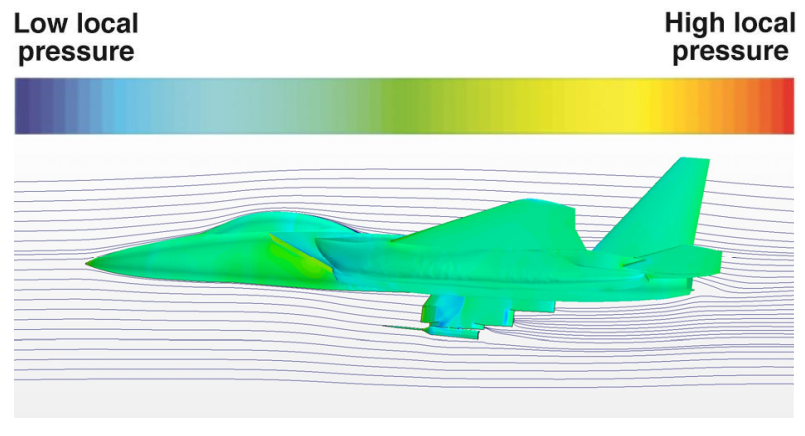

a) Mach 0.9, averaged ACN exit pressure $=1.74$ psi.

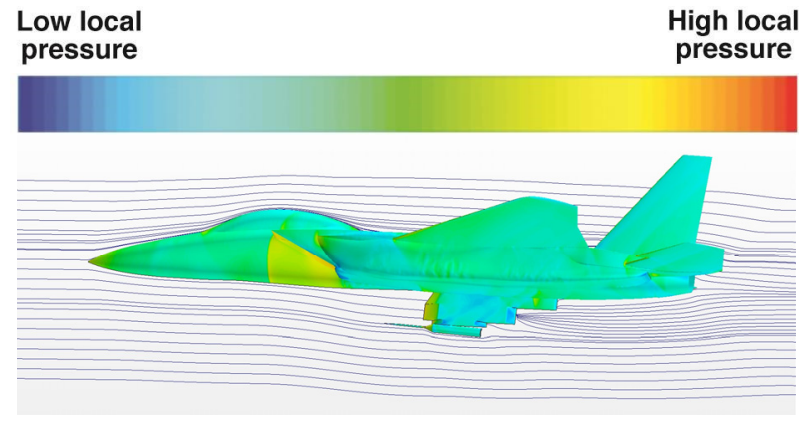

b) Mach 1.2, averaged $\mathrm{ACN}$ exit pressure $=0.98 \mathrm{psi}$.

Figure 7. Static pressure contours from inviscid/Euler F-15 airplane analysis, with full stack and non-flowing $\mathrm{ACN}$, both at a freestream static pressure of 2 psi.

Figures 8(a) and 8(b) illustrate some preliminary CFD predictions for the local flow field underneath an F-15 airplane and the ACN stack with the nozzle experiment operating. The nozzle total pressure and temperature are $150 \mathrm{psi}$ and $610^{\circ} \mathrm{R}$, respectively. Similar to Fig. 6 and Fig. 7, the static pressure contours on the airplane for the Mach 0.9 flight condition are shown in Fig. 8(a), and the static pressure contours for the Mach 1.2 flight condition are shown in Fig. 8(b). The averaged ACN exit pressure for the transonic flight condition is 1.73 psi, and the supersonic flight condition is only $0.26 \mathrm{psi}$. At this supersonic flight condition, the ACN exit pressure is only a small fraction of the freestream static pressure, emphasizing that the design of the ACN flight experiment for supersonic flight conditions must take into account the nozzle installation and plume effects. These results also show the advantage of slightly pitching-up the attitude of the RFS, revealing that the ACN exhaust flow is angled away from the airplane before straightening out to be parallel with the freestream flow field. 


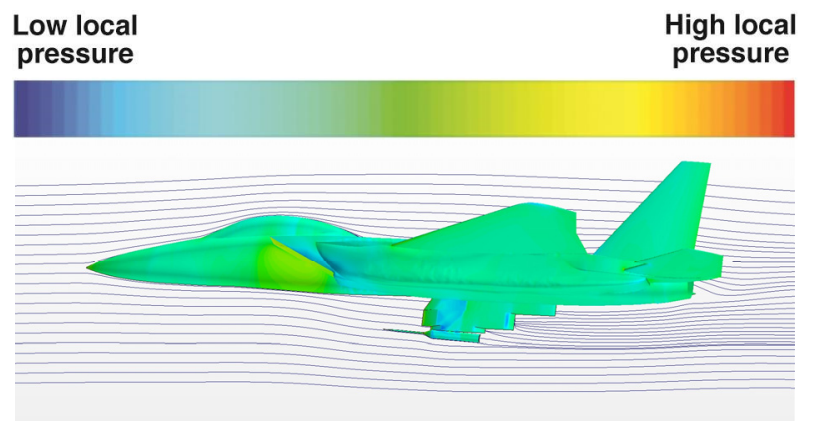

a) Mach 0.9, averaged $\mathrm{ACN}$ exit pressure $=1.73 \mathrm{psi}$.

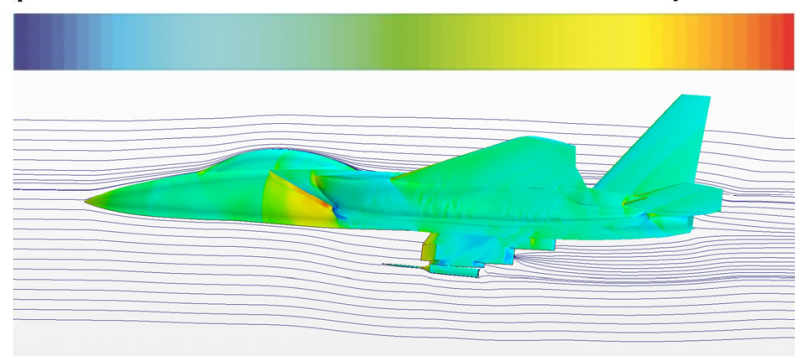

b) Mach 1.2, averaged ACN exit pressure $=0.26$ psi.

Figure 8. Static pressure contours from inviscid/Euler F-15 airplane analysis, with full stack and ACN operating, both at a freestream static pressure of 2 psi.

In summary, for the clean airplane only case, the $\mathrm{ACN}$ exit pressure from both the transonic and supersonic cases do not vary much from the freestream static pressure. The addition of the stack reduces the ACN exit pressure. Finally, operating the ACN reduces the ACN exit pressure still further below the freestream static pressure. This further reduction in the ACN exit pressure from the freestream static pressure is expected to be caused by the induced flow entrained by the nozzle plume (during operation). The supersonic flight Mach number produced the greatest change from the freestream pressure, especially with the ACN operating, going down to only 0.2-0.3 psi (for a freestream static pressure of $2 \mathrm{psi}$ ). In all cases, the ACN exit pressure is sub-ambient, which is beneficial from a propellant feed system design perspective.

Figures 9(a) and 9(b) provide a close-up view of the operating ACN for both the transonic and supersonic flight conditions. The RFS has been made invisible to show the internal nozzle flow more clearly. The flow in the local area of the ACN reveals no areas of concern. Shown here again, the ACN flow curves away from the airplane, and then straightens out to be parallel with the incoming freestream flow, providing sufficient clearance from the F-15 airplane. Finally, it can be seen that the ACN flow is significantly over-expanded at these flight conditions.

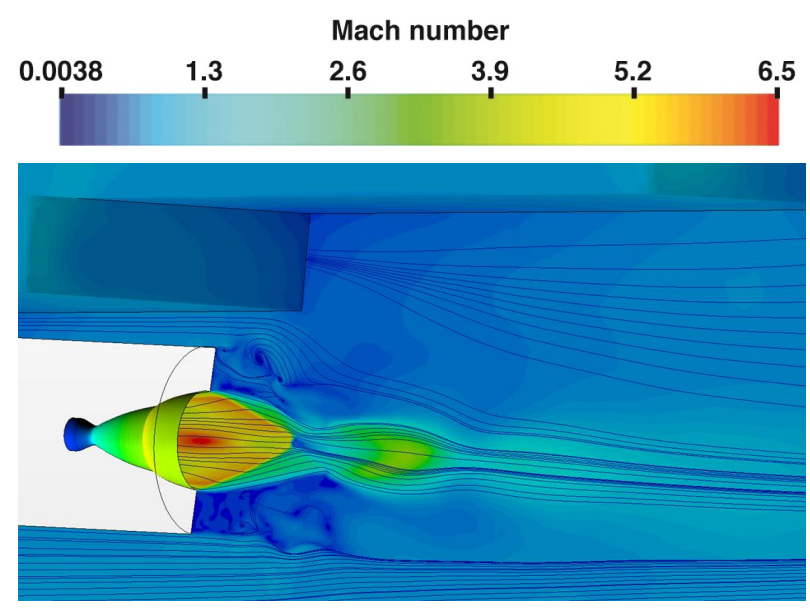

a) Freestream Mach 0.9.

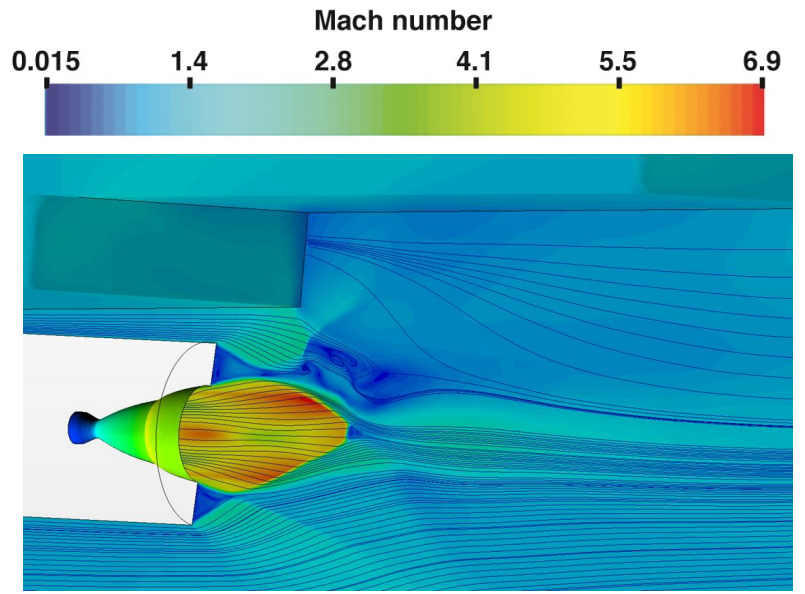

b) Freestream Mach 1.2.

Figure 9. Close-up view of Mach contours from inviscid/Euler F-15 airplane analysis, with full stack and ACN operating, both at a freestream static pressure of 2 psi. 


\section{Conceptual Design for the Cold-Flow Nozzle Operational Flights (Phase II)}

Phase II of the dual-bell nozzle flight-research campaign is to conduct flights while operating cold flow through the nozzle test articles. Flight operations with two different nozzles are planned: flights with a dual-bell nozzle; and flights with a CB nozzle. The rationale behind conducting Phase II of the flight-research campaign is two-fold: (1) to allow cold-flow data from MSFC static testing to be leveraged and compared against flight-test data; and (2) to permit an intermediate or build-up approach in system complexity (prior to tests with reacting flow), partially for risk mitigation purposes. This section will focus on the conceptual design of the cold flow propellant feed system, as well as the nozzle scaling and preliminary performance analysis. The primary goal of this conceptual design is not to provide the final design solution, but rather, to provide design options and insight into the feasibility of operating a dual-bell nozzle system with the F-15/PFTF as the flight testbed.

\section{A. Propellant Feed System Design: Option 1}

The conceptual design for the Phase II flight system is based on a schematic of the propellant feed system, which is shown in Fig. 10. The dual-bell nozzle cold flow propellant feed system is a propulsion system that uses highpressure gaseous nitrogen $\left(\mathrm{GN}_{2}\right)$ propellant. The entire system is contained within two primary structures: the PFTF OML, and the RFS OML. The propellant feed system design also draws on AFRC experience with several projects, but primarily on the propellant feed systems for the X-43A Hyper-X program and on the Orion Abort Flight Test project. $^{9}$
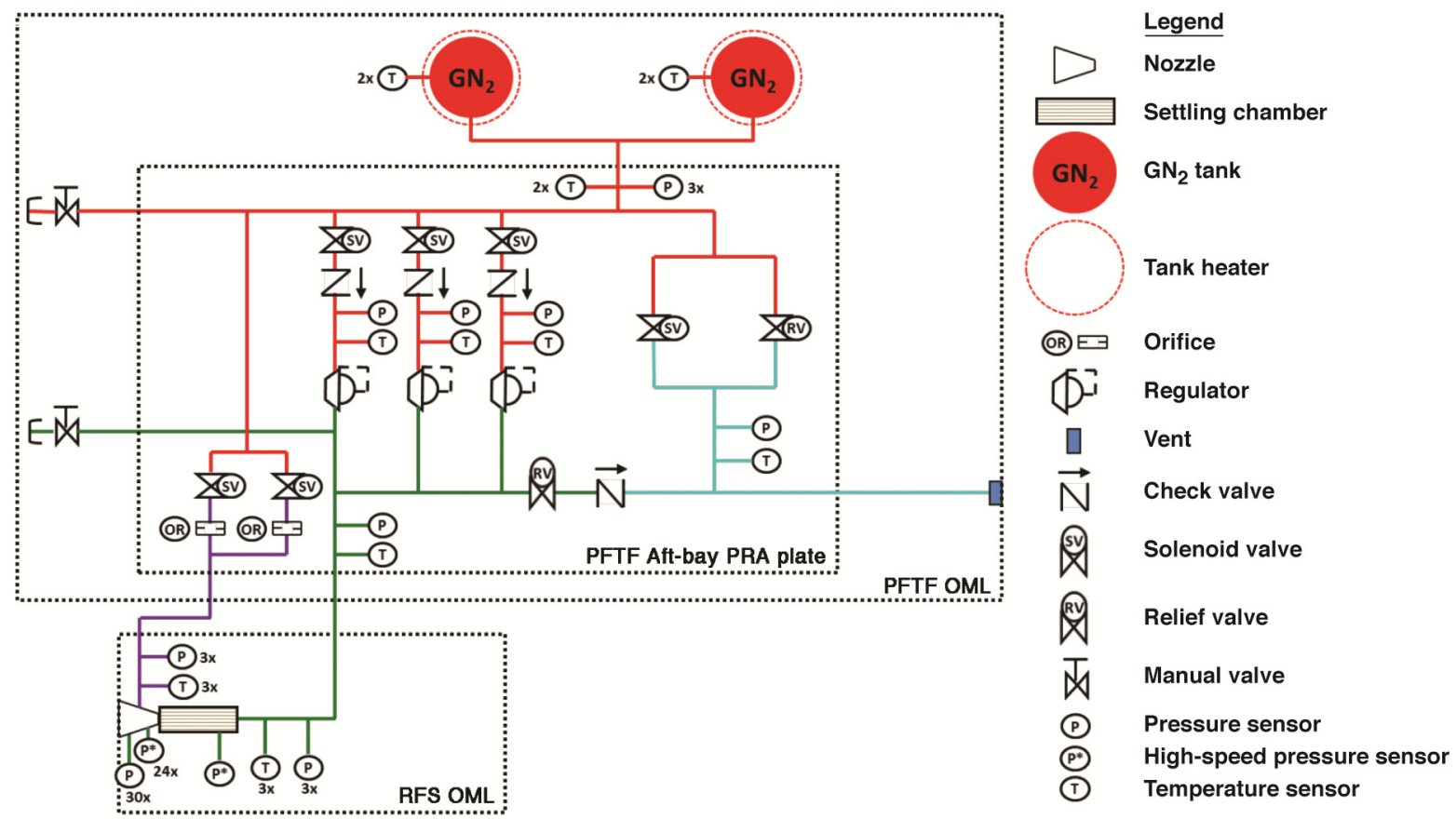

Figure 10. Propellant feed system schematic, option 1.

The propellant feed system utilizes two propellant tanks that both deliver high-pressure $\mathrm{GN}_{2}$ to a pressure reducing assembly (PRA). The purpose of the PRA is to receive high-pressure $\mathrm{GN}_{2}$ and reduce it to an appropriate pressure for test article operation. Components of the PRA are also designed to prevent feed system over-pressurization, for flight safety and for system health. The PRA also includes a film coolant system, or a bleed system, as shown by the purple feed lines in Fig. 10. The film coolant system will be injected between the first and the second bells, and will be used to control the nozzle flow state, facilitating the plume mode transition (filling the second bell). Pressurization and depressurization of the system during ground operations can be accomplished through the service valve assembly, via two manual service (fill/drain) valves accessed from the exterior of the PFTF. One service valve will provide access to the high-pressure side, while the other will provide access to the low-pressure side. The vent assembly consists of a non-propulsive vent used to direct the exhaust from the vent and relief valves to the rear of the PFTF. 
The test article assembly will be integrated within the RFS and will be easily interchangeable for either type of nozzle (either for a CB nozzle or for a dual-bell nozzle). Propellant lines connect the various subassemblies together, and pressure and temperature transducers will be used in every isolated segment of the system. These measurements will enable a real-time health monitoring assessment during flight, as well as enable a real-time and post-flight performance assessment of the nozzle experiment and the propellant feed system. Figure 11(a) shows an isometric view of the PFTF external shell, and Fig. 11(b) shows the primary components of the PFTF propellant feed system (from the same angle). The two propellant tanks are vertically mounted in the aft bay of the PFTF and are shown in red and blue. The PRA plate is also mounted in the aft bay of the PFTF and is located between the two propellant tanks, shown in orange in Fig. 11(b). Several components will be mounted to the PRA plate, as noted within the schematic. An additional, smaller aft-bay PRA plate is also available for mounting components, if component packaging proves challenging.

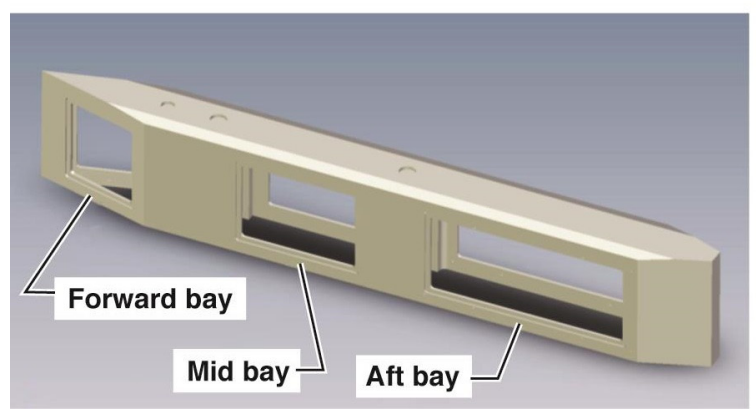

a) PFTF external shell.

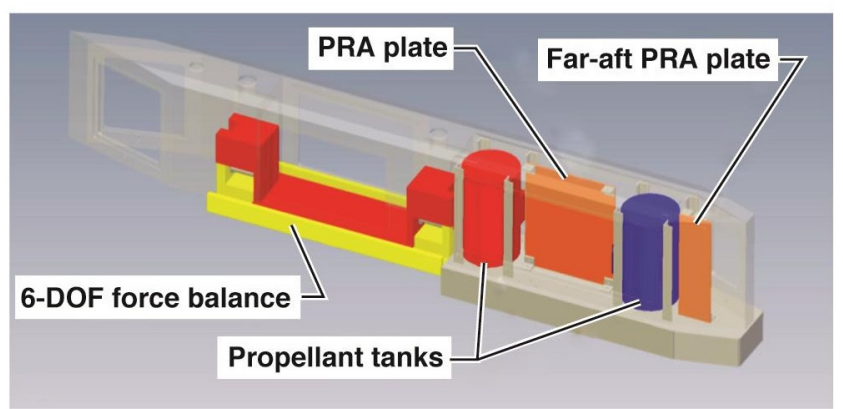

b) PFTF internal view with primary components.

Figure 11. F-15/PFTF for the ACN experiment.

The two propellant tanks will be vertically mounted, identical, and made of stainless steel, with a maximum expected operating pressure (MEOP) of 3,500 psi. Each propellant tank has an estimated volume capability of 409 cubic inches. Although a composite overwrapped pressure vessel (COPV) would provide a far more efficient means of high-pressure gaseous propellant storage, the propellant tanks shown in this conceptual design are also intended to be compatible with propellants that will be used during Phase III flights. The hardware selected within this conceptual design was also greatly influenced by an inventory of existing flight hardware at NASA AFRC.

\section{B. Propellant Feed System Design: Option 2}

Preliminary analysis of the option 1 propellant feed system immediately revealed the minimal test duration available per F-15 flight due to the lack of propellant storage capability, as well as due to the minimal energy content of the cold-flow propellant. Several options were considered in the propellant feed system design to lengthen the test duration for the Phase II system, and most were immediately discarded. The following options were considered in greater detail, but were also ultimately discarded: (1) the addition of an on-board air compressor (discarded due to system mass and volume requirements); (2) the addition of a ram-air inlet and valve close-off system (discarded due to system complexity); and (3) utilization of air compression through the F-15 airplane engine bleed system (discarded since the compression provided is too low).

A final option that is still under consideration is the addition of PFTF side-mounted propellant tanks, and is being considered as the option 2 propellant feed system conceptual design. Both the option 1 and option 2 conceptual designs are currently being considered in a trade study to determine the final propellant feed system design. This trade study is also being considered in parallel with the conceptual design for the Phase III propellant feed system.

Figure 12 shows a schematic of the propellant feed system for the option 2 conceptual design, and should be considered in addition to the propellant feed system schematic outlined in Fig. 10. As shown in Fig. 12, two additional PFTF tank structures are added, each of which contain two propellant tanks. The four additional propellant tanks feed into the two vertically mounted PFTF propellant tanks via the smaller aft-bay PRA plate, which was shown earlier in Fig. 11(b), and components on this PRA plate are used to reduce the pressure from the four higher pressure tanks to a lower pressure for the two PFTF tanks. Figure 13(a) shows the external shell of the option 2 conceptual design with the additional side-mounted structures on the original PFTF. Figure 13(b) shows an isometric view (from the same angle) of the major components of the propellant feed system for the option 2 conceptual design. 


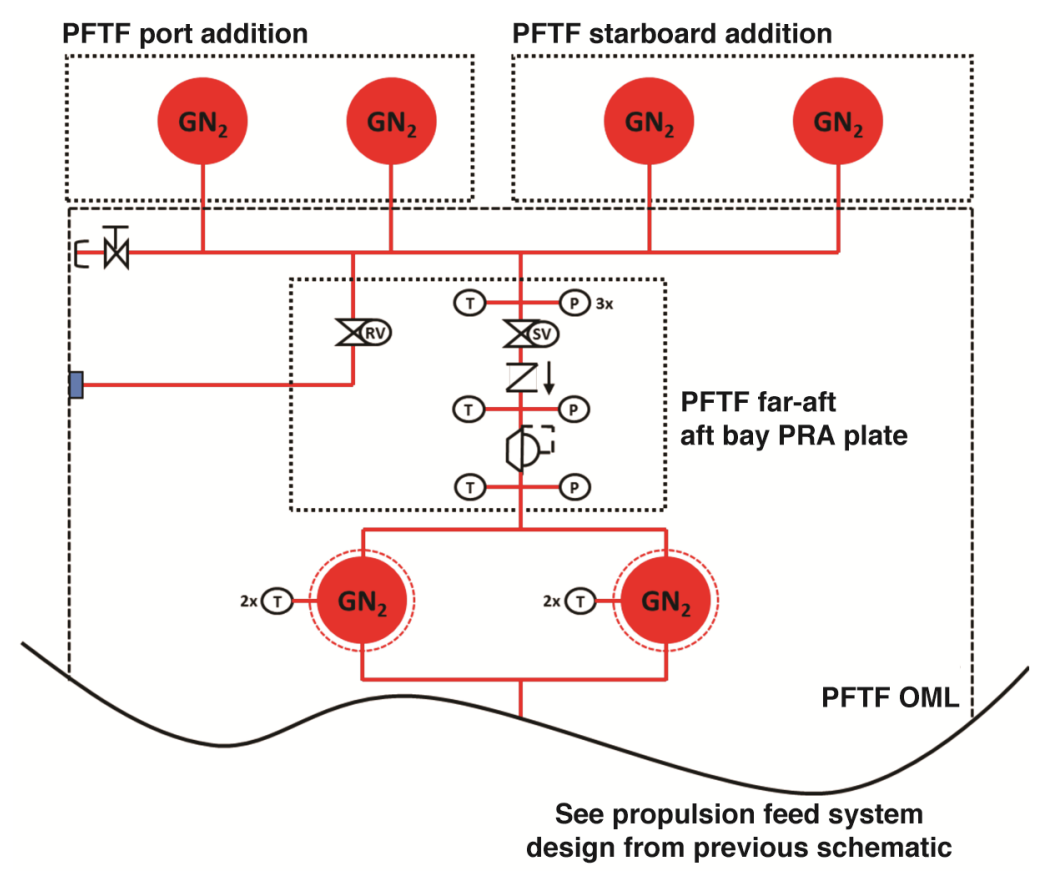

Figure 12. Propellant feed system schematic, option 2.

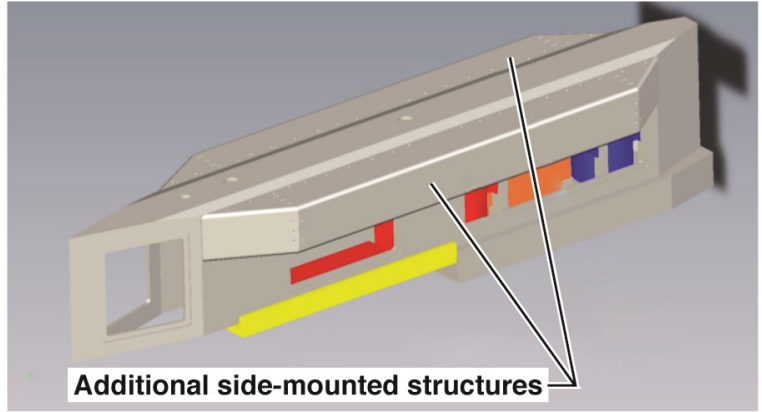

a) PFTF showing the additional side-mounted structures.

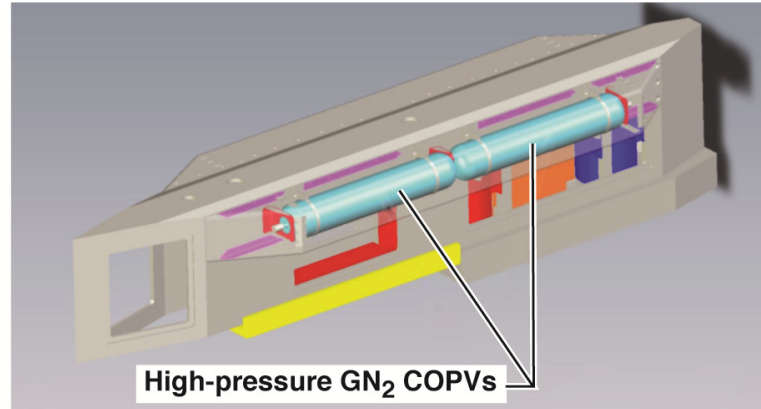

b) PFTF internal view of primary components.

Figure 13. F-15/PFTF for the ACN experiment, for the option 2 propellant feed system.

The four horizontally mounted propellant tanks will be identical. The propellant tanks selected for this conceptual design are extremely robust, each of which is a highly efficient COPV with an MEOP of 8,000 psi. Each propellant tank has an estimated volume capability of 451 cubic inches.

\section{Propellant Feed System Design and PFTF Architecture Trade Study}

The conceptual design options detailed above are intended to provide insight into the feasibility of integrating a dual-bell nozzle propellant feed system within the F-15/PFTF. Although the option 2 propellant feed system has great advantages over the option 1 system when considering the propellant loading capability, especially during Phase II (cold-flow) flights, this advantage must be weighed against the additional complexity of modifying and building onto the flight-proven (option 1) PFTF hardware. Ultimately, the propellants chosen for the Phase III (reacting flow) conceptual design will greatly influence the final architecture of the Phase II propellant feed system design, since the goal is for these systems to be fundamentally similar. Also, the external configuration for Phase I must be identical to all Phase II and Phase III flights for the external flow-field survey to be consistent. A trade study is currently in progress on the appropriate propellant feed system and PFTF architecture for dual-bell nozzle flight research throughout all three phases of the flight-research campaign. The final design will also be influenced by the hardware that currently exists at NASA AFRC and NASA MSFC. 


\section{ACN System Instrumentation}

Top-level details of the instrumentation requirements are noted within the propellant feed system schematic for each of the design options. Several measurements will be made throughout the system to enable a real-time health monitoring assessment during flight, as well to enable a real-time and post-flight performance assessment of the nozzle experiment and the propellant feed system.

Inside the dual-bell nozzle test article, there will be three static pressure measurements upstream of the settling chamber and one high frequency pressure measurement in the settling chamber just upstream of the nozzle throat, as noted in Fig. 10. These pressure measurements, along with three thermocouples, will be used to measure the working fluid total conditions (i.e. the combustion chamber conditions) of the test article. These measurements will be used to determine the performance metrics by which the performance of a nozzle is assessed.

Downstream of the nozzle test article throat, 30 static pressure measurements and 24 high frequency pressure measurements will be required. These 54 pressure measurements will be used to determine the behavior of the flow within the dual-bell nozzle; whether the nozzle is in mode 1 or mode 2, and how the flow transitions between modes. The flight nozzle will follow the same instrumentation philosophy as was conducted for previous tests at MSFC, as shown in Fig. 1.

As noted earlier, film coolant will be injected between the first and the second bells and will be used to control the nozzle flow state. Three static pressure measurements and three thermocouples in the film coolant manifold will be required to quantify the film coolant mass flow and properties.

Two separate video camera locations will be required for recording and monitoring each of the nozzle tests. One camera location will be within a small aeroshell on an airplane engine nacelle, and the other will be within the aft-bay of the PFTF. From each of the two camera view points, two video capabilities will be provided: (1) a highresolution/frame-rate video, to permit a qualitative assessment of nozzle performance, which will complement the quantitative performance instrumentation; and (2) a medium-resolution/frame-rate video, for nozzle operation situational awareness and safety reasons. The high-resolution/frame-rate video will be recorded and viewed after each flight, and this video will not be down-linked real-time. The medium-resolution/frame-rate video will be made available for real-time monitoring by the flight-test engineer in the back seat of the F-15, and this video will also be down-linked for real-time monitoring and observation by those within the AFRC flight research control room. In addition, infrared cameras are also being considered for Phase III of the flight-research campaign.

\section{E. Dual-Bell Nozzle Design Philosophy}

The dual-bell nozzle has been predicted to achieve a higher performance over the CB nozzle, both analytically and through static test data. This predicted higher performance is possible because a dual-bell nozzle expands the nozzle flow to two different area ratios, or nozzle modes, during vehicle ascent. The dual-bell nozzle design philosophy will likely be driven by the desire to maximize the performance of the nozzle through control of the mode transition of the nozzle. One of the primary objectives of the flight test is to demonstrate that the dual-bell nozzle flow state can be controlled. This objective will require active methods for controlling the nozzle flow state; mode 1 for the relatively high back pressure of low altitudes; and mode 2 for the relatively low back pressure of high altitudes.

At the lower initial altitudes, the dual-bell flow will naturally stay in a mode 1 flow state because of the high ambient pressure. The high back pressure causes the flow to separate at the geometric inflection point between the two bells. Since the ambient pressure decreases with increasing altitude, the nozzle flow will expand to fill the second bell at these higher altitudes. The natural tendency of any nozzle is to flow full too soon, and the dual-bell nozzle is no different. Without active control, the flow of a dual-bell nozzle will attempt to flow full into the second bell prematurely, which would result in reduced thrust (due to overexpansion) and a less-than-optimal mission integrated specific impulse $\left(I_{\mathrm{sp}}\right)$. A higher mission integrated $\mathrm{I}_{\mathrm{sp}}$ can be achieved by delaying this transition. This delayed mode transition allows the first bell to produce thrust at its near-optimal conditions longer and saves the second bell for later in the trajectory for near-vacuum conditions. When optimized for near-vacuum conditions, the relatively large second bell enables a higher vacuum $\mathrm{I}_{\mathrm{sp}}$ to be attained. The vacuum $\mathrm{I}_{\mathrm{sp}}$ of any Earth-to-orbit engine is by far the largest contributor to the mission integrated $\mathrm{I}_{\mathrm{sp}}$ of a rocket engine.

Likely methods to control mode transition will involve throttling the main combustion chamber pressure and/or variation of the nozzle film coolant flow rate. It is envisioned that the second bell will be a thin-walled, radiatively-cooled nozzle that would benefit from nozzle wall film coolant. This film coolant will be injected near the inflection point between the two bells. It is also believed that changes in the injected film flow can induce the second bell to flow full at the desired time. 
A representative Space Transportation System (STS) trajectory is used as a starting point for a dual-bell nozzle design. Figure 14(a) illustrates the Space Shuttle Main Engine (SSME) power level and normalized nozzle pressure ratio (NNPR) for a representative STS trajectory. The NNPR is defined in equation 1.

$$
N N P R=N P R / N P R_{\text {design }}=\left(P_{c} / P_{\text {amb }}\right) /\left(P_{c} / P_{\text {amb }}\right)_{\text {design }}
$$

When NNPR is 1.0, the nozzle is at its design altitude: the altitude where the nozzle area ratio is most efficient. The design altitude for the SSME is approximately $39 \mathrm{kft}$, as indicated in Fig. 14(a). Values of NNPR less than 1.0 indicate the nozzle flow is overexpanded, or the nozzle is operating below its design altitude. As indicated in Fig. 14(b), thrust is reduced because the nozzle exit pressure is below ambient pressure (i.e. drag). Values of NNPR greater than 1.0 indicate the nozzle flow is underexpanded, or the nozzle is operating above its design altitude. When above the design altitude, the $\mathrm{I}_{\text {sp }}$ produced is less than would be possible if the nozzle had a larger area ratio. For any launch vehicle the choice of the engine design altitude is a balance between needing thrust to get off the launch pad (best with small nozzle area ratios) and trying to maximize the vacuum $\mathrm{I}_{\mathrm{sp}}$ (best with large nozzle area ratios).

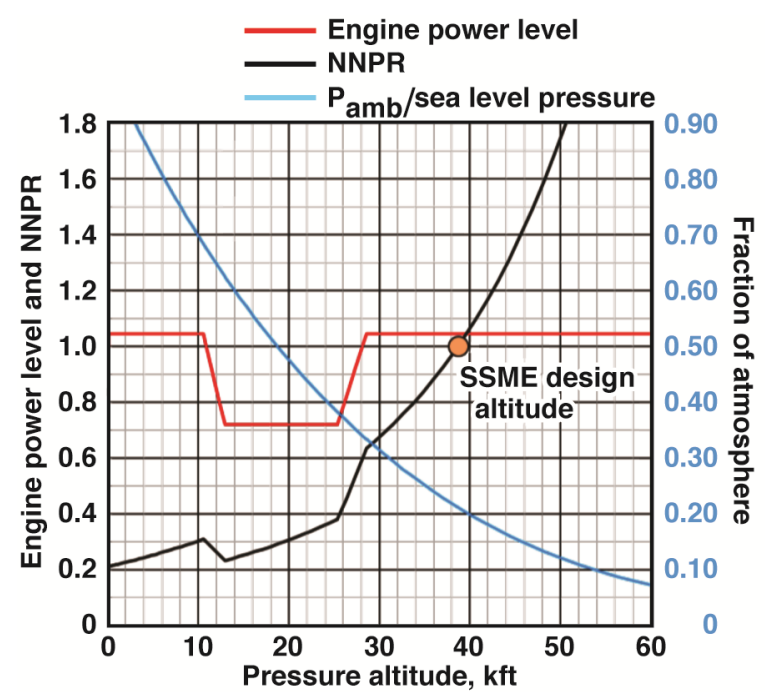

a) Typical engine parameters on the STS/SSME.

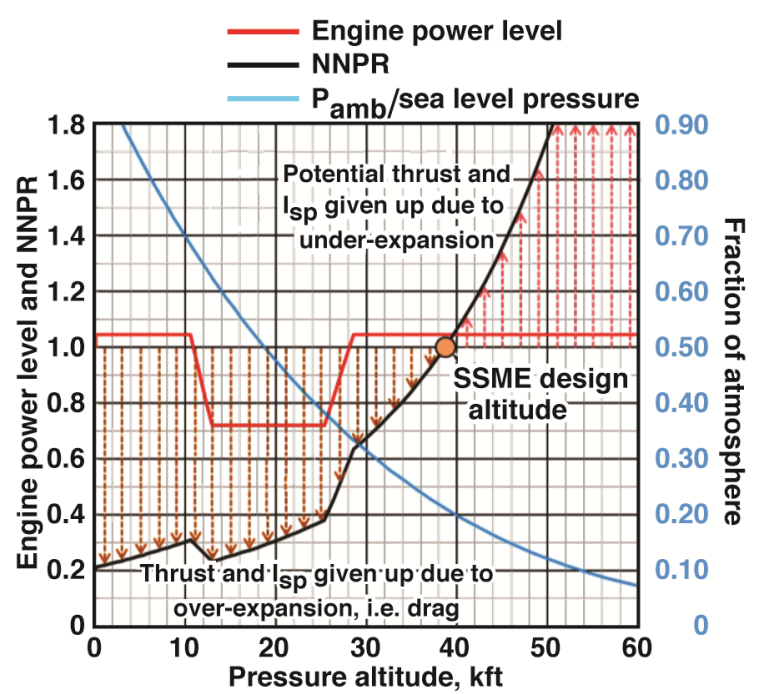

b) Performance losses due to off-design altitude nozzle operation.

Figure 14. Engine parameters based on an STS trajectory with the SSME.

Figure 15(a) helps to explain the drop in SSME power level in the STS trajectory. The STS reduced the SSME thrust to keep the flight dynamic pressure loads on the vehicle at manageable levels. The modulation of the engine $\mathrm{P}_{\mathrm{c}}$ for this thrust bucket lends itself to incorporation of a dual-bell nozzle in a flight trajectory, not just for STS-like launch vehicles, but for any vehicle with an engine-throttling capability.

The basic approach envisioned is to start the engine at full power level with the first bell of the dual-bell nozzle flowing full. The first bell would have a relatively low area ratio, producing higher thrust at lower altitudes. A notional mode 1 design altitude and an NNPR curve are sketched in dark green in Fig. 15(b). As altitude increases, the ambient pressure $\left(\mathrm{P}_{\mathrm{amb}}\right)$ decreases, and the dual-bell nozzle will begin to approach the NPR at which it will transition to mode 2. At this time, the engine would be throttled back to keep the mode transition from occuring, at the same time reducing thrust for the thrust bucket. Once the launch vehicle has passed through maximum aerodynamic pressure, the engines would be throttled up rapidly to induce mode transition, flowing full in the second bell of the nozzle. A notional NNPR curve for the second bell is sketched in light green in Fig. 15(b). The second bell would have a relatively large area ratio, with a relatively high design altitude (notionally shown as the light green dot), thus increasing the potenial vacuum $\mathrm{I}_{\mathrm{sp}}$. The limit on the mode 2 area ratio would be set by trades on nozzle physical size, nozzle mass and stiffness, and managing the necessary, but momentary induced drag due to overexpansion of the mode 2 flow during nozzle mode transition. 


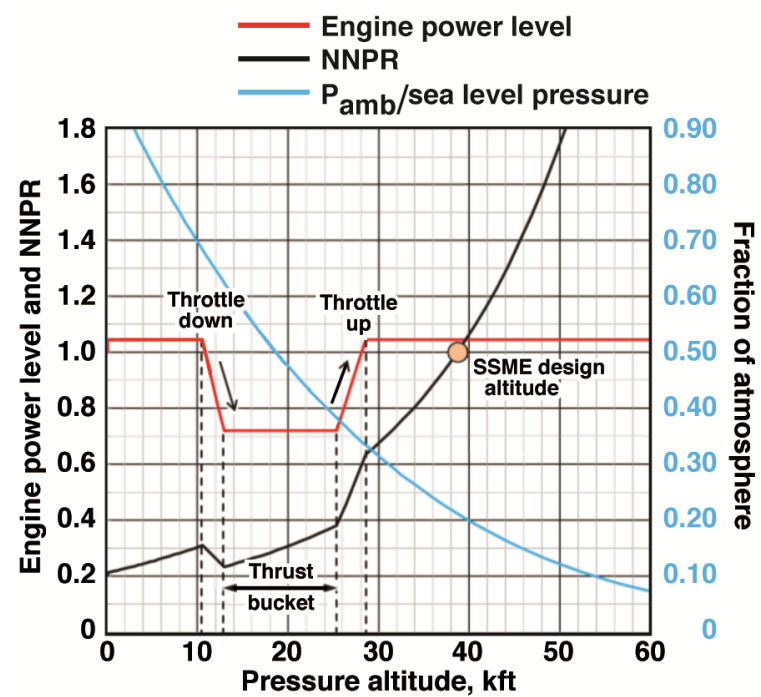

a) Description of the thrust bucket.

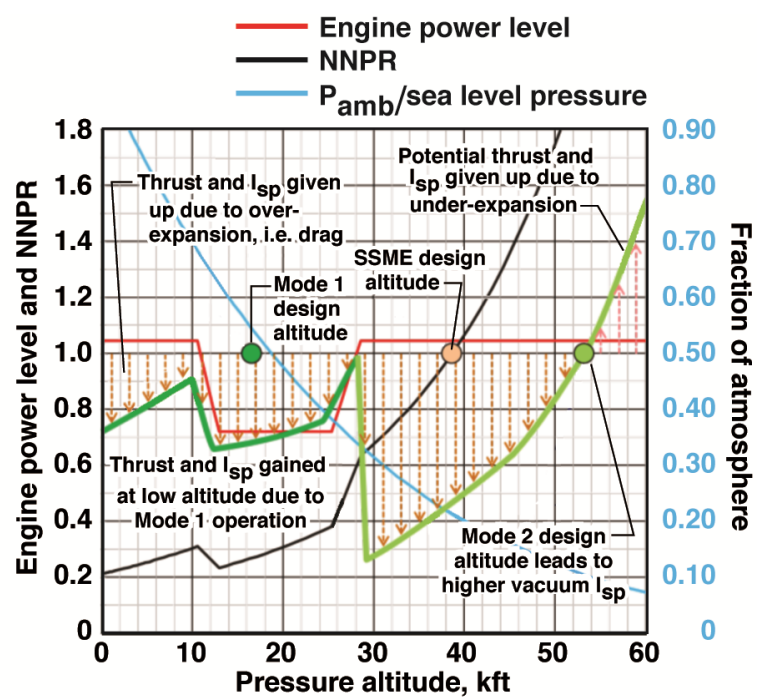

b) Notional NNPR curves and design altitudes for a dual-bell nozzle.

Figure 15. Engine parameters based on an STS trajectory with the SSME.

The key to deriving the maximum possible benefit from a dual-bell nozzle is the ability to control the mode transition while the nozzle is exhausting into a relevant flight environment. With a predictable and controllable mode transition, the design altitudes (i.e. area ratios) of the first and second bells can be optimized for the greatest possible performance that a dual-bell nozzle offers.

\section{F. Dual-Bell Nozzle Design Approach}

Figure 16 illustrates the general approach for the dual-bell nozzle test article design for flight on an F-15 airplane. The key design variables of the dual-bell nozzle during F-15 flight testing are shown on the representative profiles at the bottom of Fig. 16. The test article mode is shown on the first profile and indicates that the dual-bell nozzle is initially in mode 1 . After throttle down, the nozzle will remain in mode 1 . The transition to mode 2 will be induced during the throttle-up portion of the profile, by increasing the $\mathrm{P}_{c}$ of the test article, which is shown on the second profile. The initial $P_{c}$ setting is $150 \mathrm{psi}$, as shown for this example. The throttle-down results in a $P_{c}$ of $105 \mathrm{psi}$ or to a $70 \%$ power level in the thrust bucket. The throttle-up would require a $\mathrm{P}_{\mathrm{c}}$ of approximately $300 \mathrm{psi}$ to induce transition into mode 2.

Throttling up to $300 \mathrm{psi}$, or twice the initial $\mathrm{P}_{\mathrm{c}}$, is done for these dual-bell nozzle flight tests to compensate for the fact that the back pressure will not rapidly decrease during tests on the F-15 airplane. One difference between a launch vehicle trajectory and the planned F-15 dual-bell nozzle flight tests is that the launch vehicle is continuously flying higher during engine commands within the thrust bucket, and $\mathrm{P}_{\mathrm{amb}}$ continues to drop rapidly. Hence, the NPR increases continuously due to the decreasing $\mathrm{P}_{\text {amb }}$. The nozzle operational tests during Phase II with an F-15 airplane will be at a constant altitude, or with minimal variation of $\mathrm{P}_{\mathrm{amb}}$ over the relatively short test times. For this reason, the NPR during flight testing will be increased by increasing the $P_{c}$ of the test article. Increasing NPR either way will produce the same nozzle flow fluid dynamics. After the initial nozzle operational flights at constant F-15 flight conditions, future tests may include nozzle operation on an F-15 airplane while rapidly varying the flight conditions.

The NPR for the test article is shown on the third profile, and the NNPR profile is shown on the last profile. NNPR is a similarity parameter that enables cold flow test articles to simulate hot fire nozzle performance. 


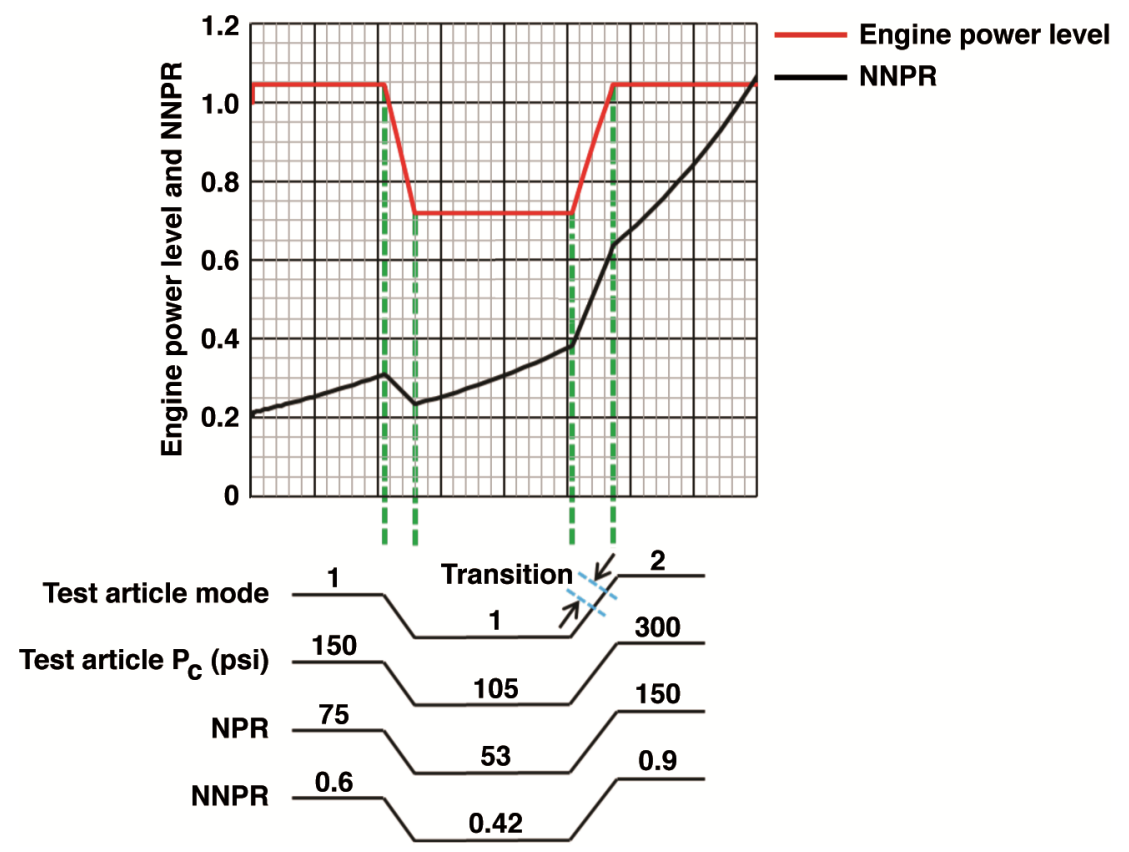

Figure 16. Nozzle test article design variables.

\section{G. Dual-Bell Nozzle Sizing Trades}

A one-dimensional test article nozzle sizing trade was done for the cold flow test article with the working fluid as $\mathrm{GN}_{2}$. The throat area was an input, and assumptions were made as to the total temperature and total pressure for the $\mathrm{GN}_{2}$, enabling an estimate of the mass flow rate. Consumption of the available $\mathrm{GN}_{2}$ is one of the primary design constraints for sizing the test article. The test article area ratios were chosen based on the expected ambient pressures during operational tests on an F-15 airplane. The ratios of the first and second bell $\mathrm{NPR}_{\text {design }}$ values were based on the cold flow test article previously tested at MSFC. With a throat area defined, the nozzle exit area and diameter were then calculated, and a one-dimensional thrust equation was used to estimate the thrust generated. Another constraint in the sizing trade is that the thrust should be large enough and steady conditions should last long enough that thrust can be measured accurately on the PFTF force balance. PFTF force balance limitations and expected accuracy have previously been reported. ${ }^{4}$ Another design consideration is that the cold flow flight-test article should be sized so that it can also be tested in the MSFC NTF. The NTF test data will establish the reference performance for the dual-bell nozzle. Based on the initial trades it appears the flight-test article will fit within the NTF test capability.

Figures 17(a) and 17(b) illustrate some results from the one-dimensional sizing trades. The mass flow rate for two different throat diameters at three flight-test altitudes is shown in Fig. 17(a). The one-dimensional thrust corresponding to mode 1 and mode 2 operations is shown in Fig. 17(b). Figure 18 plots the mass fraction consumed for test times of approximately six seconds, with the option 2 propellant feed system architecture. This plot shows that if the flight tests are at low altitudes, requiring a high test article $\mathrm{P}_{\mathrm{c}}$ (to maintain desired NPR), there is an upper limit to the size of the test article. Conversely, Fig. 18 also shows that there is plenty of design space to develop a test article of a reasonable size, based on the region below the black dashed line. 


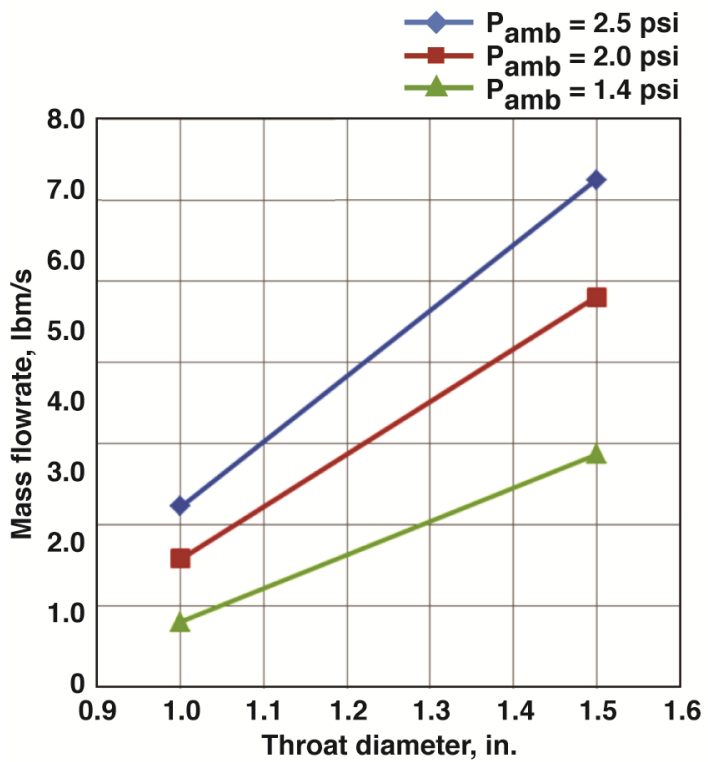

a) Mass flow as a function of throat size and back pressure.

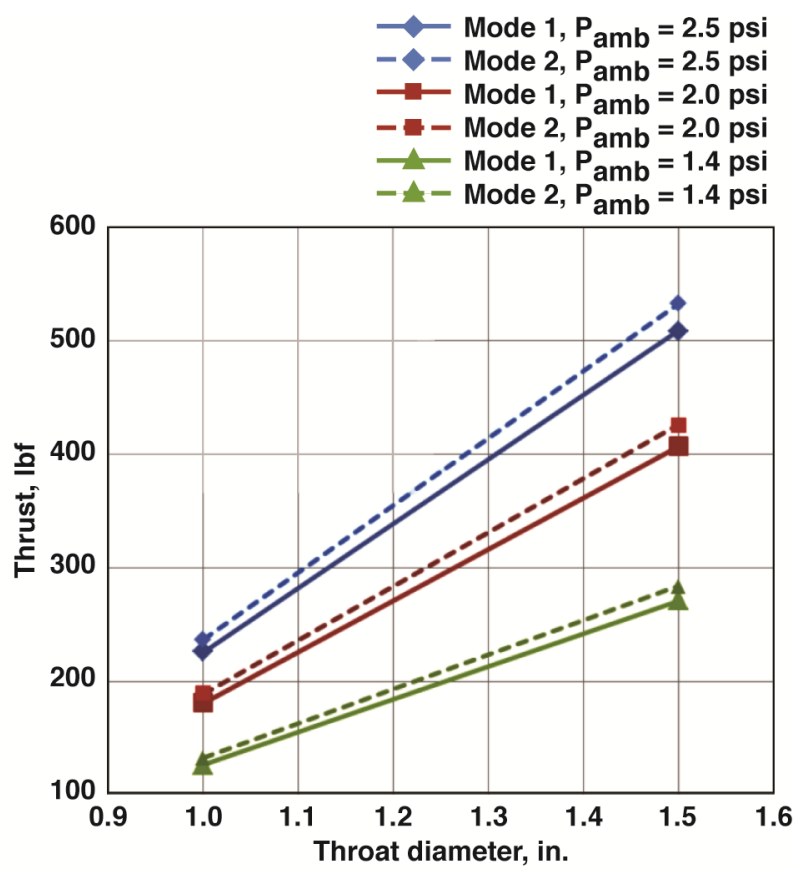

b) Thrust generated as a function of throat size, back pressure, and operational mode.

Figure 17. Test article performance as a function of throat size and back pressure.

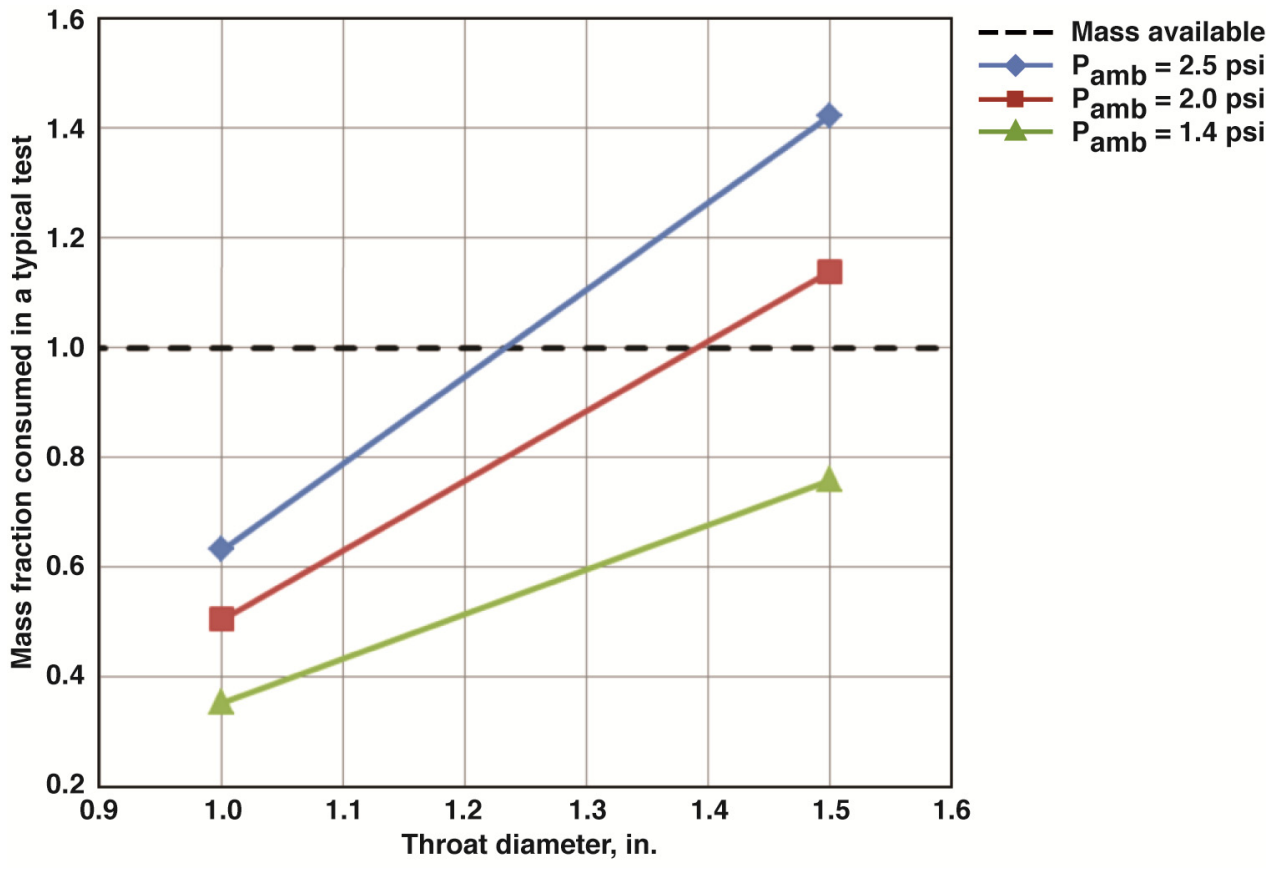

Figure 18. $\mathrm{GN}_{2}$ propellant consumed as a function of throat size and back pressure. 
Figure 19 plots the approximate nozzle test conditions within the F-15/PFTF flight envelope. The F-15/PFTF flight envelope is a subset of an F-15 flight envelope. ${ }^{1}$ Three different altitude conditions are noted within Fig. 19, with the Mach number range of interest also indicated. Nozzle test points at high subsonic and low supersonic Mach numbers are required to match those of typical launch vehicle trajectories in order to examine nozzle performance and behavior during operation into a relevant flight environment. Nozzle tests conducted during Phase II of the flight-research campaign are expected to be conducted while the F-15 airplane is maintaining constant flight conditions. A large variation in the flight Mach number is not required within each test; however, nozzle tests with an increasing freestream Mach number may be of value.

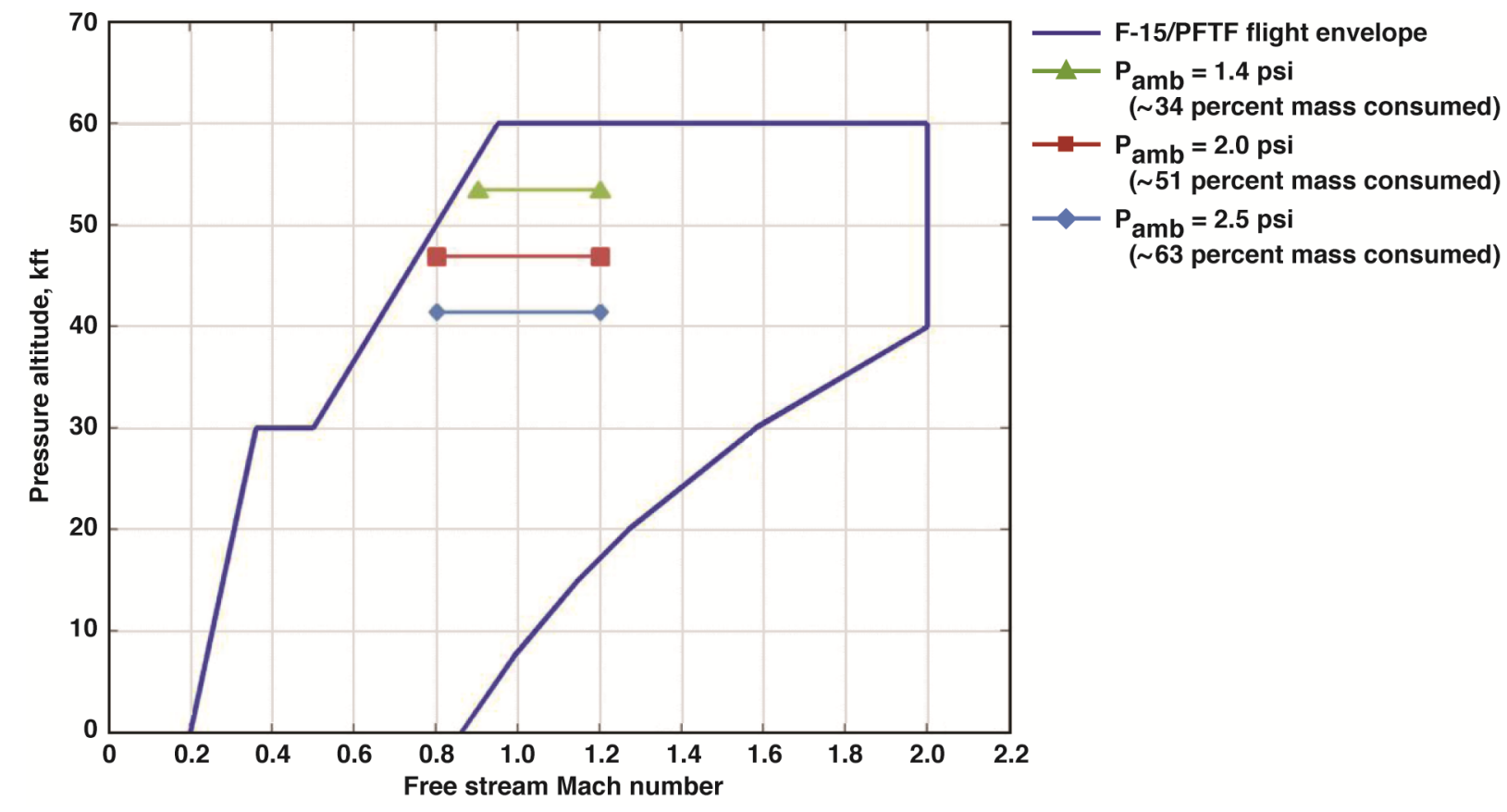

Figure 19. Approximate mapping of Phase II flight-test points on the F-15/PFTF flight envelope.

\section{Conclusion}

NASA AFRC and NASA MSFC have formed a collaborative effort to advance the TRL of the dual-bell rocket nozzle. This paper expands on the effort initially proposed, to conduct dual-bell nozzle research during captive-carried flight on the NASA F-15/PFTF, permitting this nozzle to be tested in a relevant flight environment while under well-controlled flight conditions. The ultimate goal of this research is to utilize the F-15/PFTF as a flight testbed to help quantify the performance benefit with the dual-bell nozzle, as well as to advance its TRL. The conceptual designs presented here are focused on providing insight into the feasibility of conducting dual-bell nozzle flight research with a NASA F-15 airplane. These conceptual designs are based on the utilization of existing flight-proven hardware to the greatest extent possible, with the F-15/PFTF as the flight testbed; a testbed that has been utilized on previous captive-carried flight research experiments.

The feasibility assessment of this effort was aided by an initial inviscid/Euler CFD analysis under various flight conditions. Despite the disturbances created by the F-15/PFTF flight testbed, it can be seen that smooth flow exists underneath the airplane near the nozzle for the transonic and supersonic conditions analyzed. This analysis also included flow-field predictions with and without nozzle operation, while operating with $\mathrm{GN}_{2}$ propellant during Phase II flights. A viscous/Navier-Stokes CFD flow field analysis will be documented in a separate publication. All CFD predictions of the external flow field and of the nozzle operation will eventually be validated against flight data, and nozzle operational flight data will also be compared with MSFC NTF nozzle static test data.

Two conceptual design options were presented for the Phase II test article propellant feed system, and a trade study is currently in progress to aid in the selection of the final system. Under both options, a relatively simple $\mathrm{GN}_{2}$ system is anticipated, and the final propellant feed system chosen will be fundamentally consistent with the final pressure-fed reacting-flow propellant feed system design planned for Phase III of the flight-research campaign. An 
instrumentation system is planned to aid with an in-flight health and status assessment of the propellant feed system, as well as to fully characterize the performance benefit of the dual-bell nozzle.

The dual-bell nozzle design philosophy was presented with discussion of how this technology could ultimately be implemented in an Earth-to-orbit launch vehicle with engine-throttling capability. The engine-throttling capability could be beneficial for optimizing dual-bell nozzle performance. A conceptual method for demonstrating this technology on a cold-flow subscale dual-bell nozzle was presented. Finally, dual-bell nozzle sizing trades were presented that combine the design philosophy and design approach within the scaling constraints required for captive-carried flight on the F-15/PFTF, yielding a design space of possible dual-bell nozzle solutions for future flight testing and flight research.

Although the dual-bell rocket nozzle is predicted to have greater performance over the CB nozzle, the dual-bell nozzle has still not been adequately tested in a relevant flight environment. These predictions, both analytical and through static test data, warrant further investigation in a relevant flight environment. The preliminary analysis and conceptual design presented within this paper add greater confidence on the feasibility of conducting dual-bell nozzle research on a NASA F-15 airplane. If the dual-bell nozzle performance predictions are accurate and proven in a relevant flight environment, this performance advantage would be extremely beneficial in a full-scale rocket engine. The potential benefit is significant and could result in reducing the cost of delivering payloads to LEO.

\section{Acknowledgments}

The authors acknowledge the contributions made by a previous NASA AFRC F-15/PFTF project called the ducted Rocket Experiment (D-Rex). Conceptual designs from this effort were greatly utilized and leveraged for this dual-bell nozzle propellant feed system conceptual design.

This effort was made possible by several levels within the agency. In particular, the authors express their appreciation to the following five groups: (1) the NASA AFRC Center Chief Technologist Office; (2) the NASA AFRC Exploration and Space Technology Mission Directorate Office; (3) the NASA Langley Research Center Game Changing Development Program; (4) the NASA MSFC Technology Development and Transfer Office; and (5) the NASA Kennedy Space Center Launch Services Program. Each of these groups has shown support for the ACN project, and has continued to foster the advancement of this technology for the nation.

\section{References}

${ }^{1}$ Jones, D. S., Bui, T. T., and Ruf, J. H., "Proposed Flight Research of a Dual-Bell Rocket Nozzle Using the NASA F-15 Airplane," AIAA 2013-3954, 2013.

${ }^{2}$ Foster, C. R., and Cowles, F. B., "Experimental Study of Gas-Flow Separation in Overexpanded Exhaust Nozzles for Rocket Motors," Jet Propulsion Laboratory, Progress Report No. 4-103, 1949.

${ }^{3}$ NASA Armstrong Flight Research Center, F-15B Local Mach Investigation Instrumentation, EC04-0176-2, 2004, URL: http://www.nasa.gov/centers/armstrong/multimedia/imagegallery/F-15B/index.html\#lowerAccordion-set3-slide29 [cited 30 June 2014].

${ }^{4}$ Corda, S., Vachon, M., Palumbo, N., Diebler, C., Tseng, T., Ginn, A., and Richwine, D., "The F-15B Propulsion Flight Test Fixture: A New Flight Facility for Propulsion Research," AIAA 2001-3303, 2001.

${ }^{5}$ Palumbo, N., Moes, T., and Vachon, M. J., "Initial Flight Tests of the NASA F-15B Propulsion Flight Test Fixture," AIAA 2002-4131, 2002.

${ }^{6}$ Vachon, M. J., Moes, T. R., and Corda, S., "Local Flow Conditions for Propulsion Experiments on the NASA F-15B Propulsion Flight Test Fixture," NASA/TM-2005-213670, 2005.

${ }^{7}$ Frederick, M. A., and Ratnayake, N. A., "Flight Test Results from the Rake Airflow Gage Experiment on the F-15B Airplane," AIAA 2010-4573, 2010.

${ }^{8}$ St. John, C. W., and Frederick, M. A., "Flight Test Results of an Axisymmetric Channeled Center-body Supersonic Inlet at off-Design Conditions," AIAA 2013-3680, 2013.

${ }^{9}$ Jones, D. S., Koelfgen, S. J., Barnes, M. W., McCauley, R. J., Wall, T. M., Reed, B. D., and Duncan, C. M., "Executive Summary of Propulsion on the Orion Abort Flight-Test Vehicles," AIAA 2012-3891, 2012. 